\title{
Nitrosative Stress Induces Peroxiredoxin 1 Ubiquitination During Ischemic Insult via E6AP Activation in Endothelial Cells Both In Vitro and In Vivo
}

\author{
Rong-Rong Tao, ${ }^{1, *}$ Huan Wang, ${ }^{1, *}$ Ling-Juan Hong, Ji-Yun Huang, ${ }^{1}$ Ying-Mei Lu, ${ }^{2}$ Mei-Hua Liao, \\ Wei-Feng Ye, ${ }^{1,3}$ Nan-Nan Lu,, Dan-Yan Zhu, Qian Huang, ${ }^{4}$ Kohji Fukunaga, ${ }^{5}$ Yi-Jia Lou, \\ Ikuo Shoji, ${ }^{6}$ Christopher Stuart Wilcox, ${ }^{7}$ En-Yin Lai, ${ }^{4,7}$ and Feng Han ${ }^{1}$
}

\begin{abstract}
Aims: Although there is accumulating evidence that increased formation of reactive nitrogen species in cerebral vasculature contributes to the progression of ischemic damage, but the underlying molecular mechanisms remain elusive. Peroxiredoxin 1 (Prx1) can initiate the antioxidant response by scavenging free radicals. Therefore, we tested the hypothesis that Prx1 regulates the susceptibility to nitrosative stress damage during cerebral ischemia in vitro and in vivo. Results: Proteomic analysis in endothelial cells revealed that Prx1 was upregulated after stress-related oxygen-glucose deprivation (OGD). Although peroxynitrite upregulated Prx1 rapidly, this was followed by its polyubiquitination within $6 \mathrm{~h}$ after OGD mediated by the E3 ubiquitin ligase E6-associated protein (E6AP). OGD colocalized E6AP with nitrotyrosine in endothelial cells. To assess translational relevance in vivo, mice were studied after middle cerebral artery occlusion (MCAO). This was accompanied by Prx 1 ubiquitination and degradation by the activation of E6AP. Furthermore, brain delivery of a lentiviral vector encoding Prxl in mice inhibited blood-brain barrier leakage and neuronal damage significantly following MCAO. Innovation and Conclusions: Nitrosative stress during ischemic insult activates E6AP E3 ubiquitin ligase that ubiquitinates Prx1 and subsequently worsens cerebral damage. Thus, targeting the Prx1 antioxidant defense pathway may represent a novel treatment strategy for neurovascular protection in stroke. Antioxid. Redox Signal. 21, 1-16.
\end{abstract}

\section{Introduction}

$\mathbf{B}^{\text {n }}$ RAIN MICROVASCULAR ENDOTHELIAL CELlS provide a barrier between the bloodstream and brain that is critical in brain development, maturation, and homeostasis $(9,37)$. The balance between endothelial cell survival and death is pivotal for brain remodeling and repair (41). Increased cell death of cerebrovascular endothelial cells exacerbates inflammatory, ischemic, and degenerative brain diseases (26). Before a new strategy can be developed to counter these adverse effects of ischemia-induced endothelial dysfunction and neurovascular damage, it is necessary to define the factors responsible for ischemia-induced blood-brain barrier (BBB) damage.

Under conditions of intense oxidative stress, such as ischemia or hypoxia injury, increased generation of nitric oxide (NO) and superoxide $\left(\mathrm{O}_{2}{ }^{--}\right)$results in the formation of peroxynitrite $\left(\mathrm{ONOO}^{-}\right)(50)$. This is a short-lived highly reactive oxidant that attacks and inactivates many proteins. Specifically, $\mathrm{ONOO}^{-}$irreversibly inactivates prostacyclin

\footnotetext{
${ }^{1}$ Institute of Pharmacology, Toxicology and Biochemical Pharmaceutics, Zhejiang University, Hangzhou, China.

${ }^{2}$ School of Medicine, Zhejiang University City College, Hangzhou, Zhejiang, China.

${ }^{3}$ The Children's Hospital, Zhejiang University School of Medicine, Hangzhou, China.

${ }_{5}^{4}$ Department of Physiology, Zhejiang University School of Medicine, Hangzhou, China.

${ }^{5}$ Department of Pharmacology, Graduate School of Pharmaceutical Sciences, Tohoku University, Sendai, Japan.

${ }^{6}$ Division of Microbiology, Center for Infectious Diseases, Kobe University Graduate School of Medicine, Kobe, Japan.

${ }^{7}$ Hypertension, Kidney, and Vascular Research Center, Georgetown University Medical Center, Washington, District of Columbia.

*Both authors contributed equally to this work.
} 


\section{Innovation}

Our study is the first demonstration that nitrosative stress initiates the ubiquitination of peroxiredoxin 1 (Prx1) and subsequent disturbance of redox homeostasis in endothelial cells during ischemia-like injury. Our findings further identified E6-associated protein (E6AP) E3 ligase that ubiquitinated Prx1. Thus, repression of peroxynitrite $\left(\mathrm{ONOO}^{-}\right)$formation or E6AP knockdown dampened the ischemia-induced disturbance of Prx 1 defense signaling. Since an active Prx 1 was required for optimal neurovascular cell survival, targeting the Prx1 antioxidant defense pathway may represent a novel treatment strategy for neurovascular protection after stroke.

synthase and oxidizes tetrahydrabiopterin to dihydrabiopterin, thereby uncoupling endothelial NO synthase and directing it to generate $\mathrm{O}_{2}{ }^{\bullet-}$ in place of NO. Indeed, endothelial cells are the primary targets of nitrosative stress in cardiovascular disease, stroke, and neurodegenerative disorders $(18,48)$. Although nitrosative damage to lipids, proteins, and DNA has been implicated in neurovascular damage following cerebral ischemia, the downstream signaling mechanisms remain elusive $(13,16,17,29)$.

Peroxiredoxins (Prxs) are thiol-specific antioxidant enzymes that maintain redox balance under both normal conditions and oxidative stress $(6,7,10,28)$. Although Prx 1 is the most abundant and widely distributed member of the mammalian Prxs $(23,24)$ and is a recognized peroxidedetoxifying enzyme, its pathophysiological role during brain disease remains unclear $(38,44)$. Cultured Prxl-deficient fibroblasts have decreased proliferation and increased sensitivity to oxidative DNA damage. Prxl-deficient mice developed hemolytic anemia caused by increased erythrocytic reactive oxygen species (ROS) (34). Furthermore, mutant Hungtington $(m H t t)$ gene expression decreased Prx1 levels and increased its sulfonylation (35).

We tested the hypothesis that Prx 1 in endothelial cells in culture and in the brain in vivo is a pivotal antioxidant pathway but can be damaged by nitrosative stress during hypoxia or ischemia, thereby exacerbating injury. We report that oxygen/glucose-deprived endothelial cells ubiquitinate Prx1 by nitrosative activation of E3 ubiquitin ligase (E6associated protein [E6AP]). The outcome is that Prx1 is targeted for degradation leading to cellular redox imbalance and loss of the integrity of the endothelial BBB in mice following ischemia. Repression of $\mathrm{ONOO}^{-}$formation or E6AP knockdown dampened these disturbances of Prx 1 defense signaling in endothelial cells. The initial study was made in human umbilical vascular endothelial cells, and key observations were confirmed and extended in human brain microvascular endothelial cells (HBMECs). Thus, our results indicate that Prx1 is a pivotal molecule for the protection of endothelial cells and microvessels from ischemia-induced neurovascular damage both in vitro and in vivo.

\section{Results}

Identification of differentially expressed proteins after oxygen-glucose deprivation in endothelial cells

Two-dimensional gel electrophoresis was performed in EA.hy926 endothelial cells to identify proteins that were differentially expressed between control and oxygen-glucose deprivation (OGD)-treated endothelial cells. Figure 1A shows a silver-stained two-dimensional gel electrophoresis reference map of the OGD-treated endothelial cultures (Fig. 1A, $n=3$, lower) in comparison to the control profile (Fig. 1A, $n=3$, upper). The spots that showed a twofold or greater difference between treatments were further characterized by trypsin digestion and matrix-assisted laser desorption/ionization (MALDI) time-of-flight (TOF) mass spectrometry. Twentytwo different proteins from 36 spots were identified with high confidence (CI \% ranging from $97.5 \%$ to 100\%) (Supplementary Table S1; Supplementary Data are available online at www.liebertpub.com/ars). The identified proteins were classified into functional groups (Supplementary Fig. S1). We selected Prx1 for further study since it was implicated in oxidation-reduction balance and abundantly increased 2.5-fold after OGD treatment (Supplementary Fig. S2A).

\section{Temporal changes of Prx1 protein levels in endothelial cells after $O G D$}

Immunoblotting studies demonstrated a time-dependent increase in Prx 1 over $1-6 \mathrm{~h}$ followed by a decline after $12 \mathrm{~h}$ (Fig. 1B, C). There was a similar pattern of protein levels of heat shock protein 27 (HSP27) (Fig. 1B, C). Molecular chaperones such as HSP27 can defend against protein misfolding after sublethal stressful stimuli (4). Immunocytochemical experiments demonstrated intracellular localization of Prx 1 (Fig. 1D), which increased $6 \mathrm{~h}$ after OGD treatment in the cytosol of endothelial cells (Fig. 1D, E).

\section{Characterization of OGD-induced Prx1 ubiquitination in endothelial cells}

Unexpectedly, our Western blot data demonstrated a continual increase in the density of a broad, high-molecularweight $(>118 \mathrm{kDa}$ ) band for Prx1 starting $6 \mathrm{~h}$ after OGD treatment (Fig. 2A). A similar increase in a high-molecularweight band $(>118 \mathrm{kDa})$ was detected following OGD treatment after probing with an anti-ubiquitin antibody (Fig. 2B). The OGD-induced ubiquitination of Prx 1 was confirmed and extended in HBMECs (Fig. 3 A, B) and mouse cerebral microvascular endothelial cells (bEnd.3) (Supplementary Fig. S2B).

Inhibition of proteosomal uptake with MG132 or lactacystin also increased the high-molecular-weight isoforms of Prx1 (Fig. 2C and Supplementary Fig. S3). Probing with an anti-Prx1 antibody in ubiquitin immunocomplexes from OGD-treated endothelial cells revealed a predominant band larger than $118 \mathrm{kDa}$ (Fig. 2D and Fig. 3C). OGD-induced ubiquitination of Prx1 was confirmed by the immunoprecipitation of Prx 1 followed by immunoblotting with an antiubiquitin antibody (Fig. 2E and Fig. 3D). Consistently, Western blot analysis of cell extracts from OGD-treated cells demonstrated that high-molecular-weight conjugates of Prx1 were significantly reduced in ubiquitin-K48R-transfected endothelial cells (Fig. 2F and Fig. 3E, F).

\section{The role of Prx1 during proapoptotic cascades after OGD treatment}

Proapoptotic proteins were identified by immunoblotting of EA.hy926 cells transfected with either an empty vector or 
FIG. 1. The proteomic identification of differentially expressed proteins after OGD in endothelial cells. (A) Representative silverstained two-dimensional gel of control and OGD-treated EA.hy926 endothelial cells. Whole proteins $(450 \mu \mathrm{g})$ were separated on a nonlinear $\mathrm{pH}$ gradient (3-10) followed by $12 \%$ SDS-PAGE. (B) Time course of Prx1 and HSP27 protein levels in cell lysates of endothelial cells following OGD. Quantifications of the temporal changes of Prx1 and HSP27 protein levels are shown in (C). Immunoblots are representative of three independent experiments. $* p<0.05 ; * * p<0.01$ versus control. Immunoblotting with an anti- $\beta$-actin antibody showed equal amounts of loaded protein in each lane. (D) Changes in the immunostaining of Prx1 (green) $6 \mathrm{~h}$ after OGD. Subcellular localization of Prx1 was determined by laser confocal microscopy. Data are representative of three independent experiments. Scale bar $=20 \mu \mathrm{m}$. (E) Quantification of Prx1 immunofluorescence expressed as IOD as described in the Materials and Methods section. $* * * p<0.001$ versus control. IOD, integrated optical density; HSP27, heat shock protein 27; OGD, oxygen-glucose deprivation; Prx1, peroxiredoxin 1; SDS-PAGE, sodium dodecyl sulfate-polyacrylamide gel electrophoresis. To see this illustration in color, the reader is referred to the web version of this article at www.liebertpub.com/ars

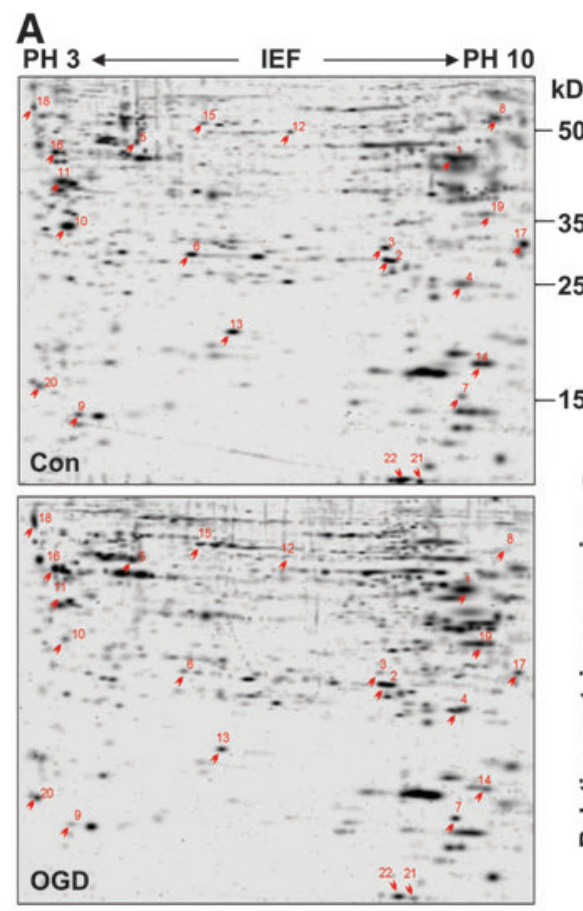

D

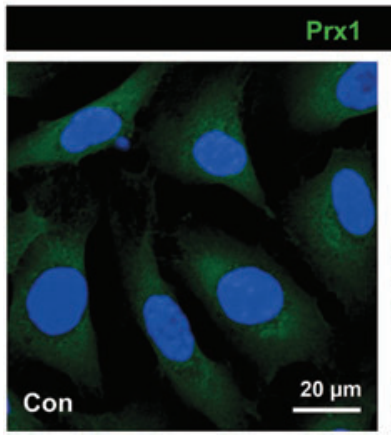

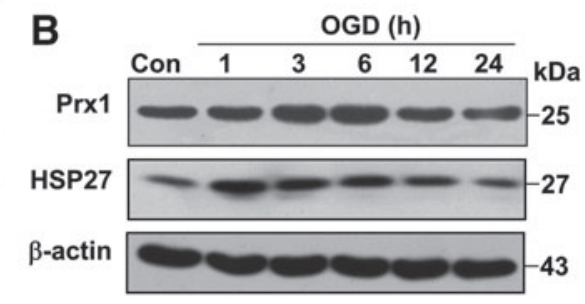

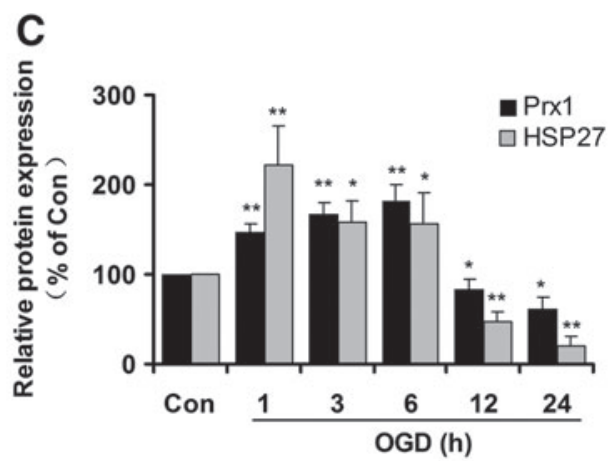

$E$

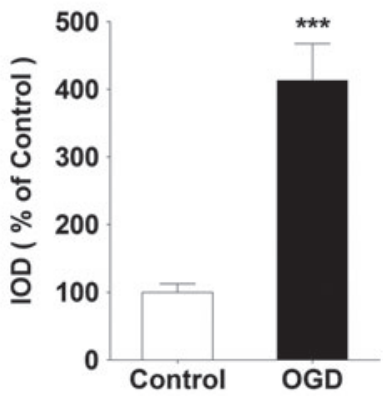

a Prxl expression vector following OGD insult (Fig. 4). Calnexin is a type I integral endoplasmic reticulum (ER) membrane chaperone involved in folding newly synthesized (glycol) proteins (8). Overexpression of Prx1 significantly inhibited calnexin, PERK, and Ire-1 $\alpha$ degradation (Fig. 4A, B) and also inhibited caspase-3 and poly ADP-ribose polymerase (PARP) cleavage (Fig. 4C, D). Exposure of vectortransfected cells to OGD for $6 \mathrm{~h}$ decreased the phosphorylation of anti-apoptotic proteins, such as phospho-ERK (Thr202/ Tyr204) and phospho-FKHR (Ser256) (forkhead transcription factor Foxo1), and also decreased the protein levels of heme oxygenase-1 (HO-1) but increased the phosphorylation of c-Jun N-terminal kinase (JNK) and P38 (Fig. 4E, F). By contrast, overexpression of Prxl after OGD injury resulted in significant upregulation of anti-apoptotic proteins in endothelial cells (Fig. 4E, F). Exposure of vector-transfected cells to OGD for $6 \mathrm{~h}$ elevated terminal deoxynucleotidyl transferase dUTP nick end labeling (TUNEL)-positive staining (Fig. 4G, H), whereas overexpression of Prx1 effectively decreased TUNEL staining (Fig. 4G, H). The apoptosis of endothelial cells was determined using flow cytometry with Annexin V-FITC/propidium iodide (PI). In contrast to control cells $(2.20 \%)$, we found that OGD treatment induced elevation in the fraction of Annexin V/PI-positive cells (49.92\%). Moreover, Prxl small interfering RNA (siRNA) transduction further exaggerated OGD-induced cell death (Fig. 4I). The present data demonstrate that Prx1 elicits an antiapoptotic effect after OGD injury in endothelial cells, coinciding with its antioxidant function in the endothelium (31).

\section{E6AP activation contributes to Prx1 stress response after $O G D$}

Since Prx 1 has been identified as a novel E6AP-binding protein (33), the present study further elaborates the role of E6AP in ubiquitination of Prx 1 during OGD. Representative blots are presented in Figure 5A and show that E6AP was activated following OGD exposure over 1-24h (Fig. 5A). Similar change of E6AP was confirmed in HBMEC (Supplementary Fig. S4A, B) and bEnd.3 endothelial cells after OGD (Supplementary Fig. S2B). Immunocytochemical analysis of the endothelial cells revealed OGD-induced strong immunoreactivity for E6AP (red fluorescence) that was undetectable in control cells (Fig. 5B-D and Supplementary Fig. S4C, D), which suggests that OGD-induced ubiquitination of Prx1 is associated with E6AP activation. 
TAO ET AL.
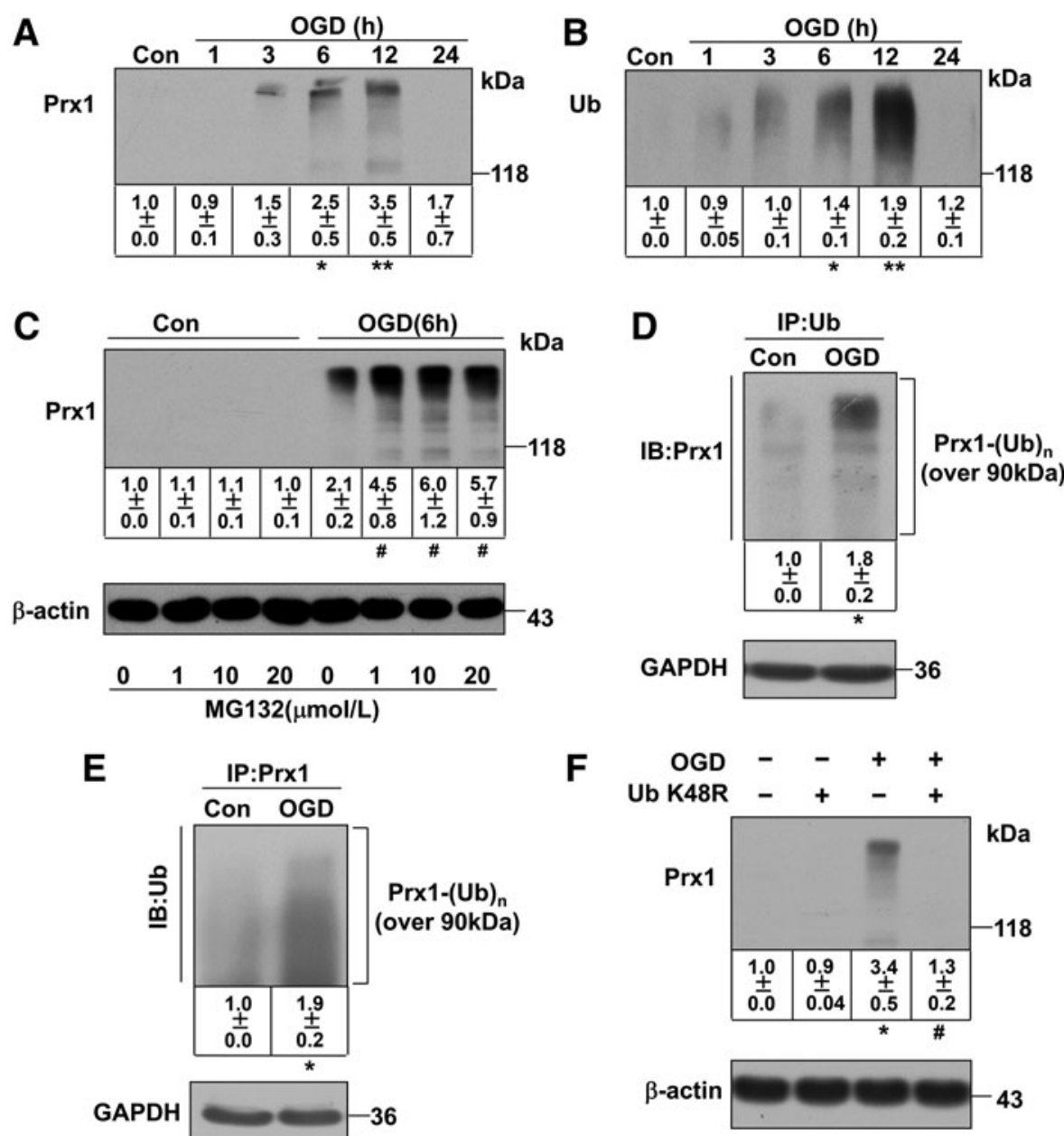

FIG. 2. OGD induces ubiquitination of Prx1 in EA.hy926 endothelial cells. (A) Temporal changes in the highmolecular-weight Prx1 isoform were observed in OGD-treated endothelial cells. The accumulated polyubiquitinylated proteins were detected by Western blot analysis with anti-Prx1 antibody. (B) Protein ubiquitination status after OGD treatment in endothelial cells. The accumulated multiubiquitinylated proteins were detected by Western blot analysis with an anti-ubiquitin antibody. (C) The changes in polyubiquitinated Prx1 were detected following OGD treatment of endothelial cells with or without proteasome inhibitors. The endothelial cells were treated with 1, 10, or $20 \mu M$ MG132 or DMSO $30 \mathrm{~min}$ before OGD. The cells were then washed, harvested after $6 \mathrm{~h}$ OGD, and analyzed for polyubiquitinated Prx 1 levels. (D) The OGD-induced ubiquitination of Prx1 was detected by the immunoprecipitation of ubiquitin followed by immunoblotting with an anti-Prx1 antibody. (E) Immunoprecipitation of Prx1 from cell lysates of OGD-treated endothelial cells followed by blotting with an anti-ubiquitin antibody. (F) The ubiquitin K48R mutant decreased OGD-induced Prx1 ubiquitination in endothelial cells. Endothelial cells were cultured and transfected with plasmid DNA encoding the ubiquitin-K48R mutant or an empty plasmid, followed by OGD and immunobloting analysis. Immunoblots are representative of three independent experiments. Data are expressed as the percentage of values of control $($ mean $\pm \mathrm{SEM}) .{ }^{*} p<0.05$; $* * p<0.01$ versus control; ${ }^{\#} p<0.05$ versus OGD.

E6AP and the active-site cysteine-to-alanine-inactivated mutant E6AP were expressed in mammalian p3869HAE6AP $C$ - $A$ cells $(22,46)$. Here, after $48 \mathrm{~h}$ of transfection, siRNA knockdown of E6AP (Fig. 5E, F) or transfection with the E6AP $C$-A mutant (Fig. $5 \mathrm{G}, \mathrm{H}$ ) both significantly blunted the ubiquitination of Prx1 in OGD-treated endothelial cells.

\section{Nitrosative stress associated with the Prx1 defensive response after OGD}

The $\mathrm{ONOO}^{-}$donor 3-morpholinosydnonimine (SIN-1) induced early dose-dependent elevation of Prx1 (Supple- mentary Fig. S5A, B) and Prx1 ubiquitination (Fig. 6A, B) in endothelial cells as detected by immunoblot, accompanied by increased Prx1 immunostaining (Fig. 6C) and activation of E6AP (Fig. 6D). Whereas increased nitrotyrosine immunostaining and E6AP immunoreactivity were observed in OGD-treated cells (Fig. 6E, F), inhibition of $\mathrm{ONOO}^{-}$with uric acid markedly reduced both nitrotyrosine and E6AP immunostaining after OGD exposure (Fig. 6E). This was confirmed by Western blot (Fig. 6G, H). A similar result was observed in endothelial cells treated with $\mathrm{ONOO}^{-}$decomposition catalysts (FeTPPS, $1 \mu M$ ) (Supplementary Fig. S6A, B). E6AP immunoprecipitates from the cell lysates were probed with anti-nitrotyrosine antibody (Fig. 6I). The results 
FIG. 3. The ubiquitination of Prx1 in OGD-treated HBMEC. (A) The time-dependent change of OGD-induced Prx1 and ubiquitin expression in HBMECs was detected by Western blot. (B) Densitometry of the Western blots for (A) was normalized by the level of $\beta$-actin as an internal control. (C) OGD-treated HBMEC endothelial cells were lysed and subjected to immunoprecipitation with antibodies to ubiquitin. The resultant precipitates were then subjected to immunoblot analysis with antibodies to Prx1. (D) Immunoprecipitation of Prx1 from lysed HBMEC with or without OGD treatment were collected for immunoblot analysis with ubiquitin antibody. (E) The ubiquitin-K48R mutant transfection attenuates Prx1 ubiquitination in OGD-treated endothelial cells. HBMEC were cultured and transfected with plasmid DNA encoding the ubiquitin-K48R mutant or an empty plasmid. (F) Densitometry of the Western blots for (E) was normalized by the level of $\beta$-actin as an internal control. Immunoblots are representative of three independent experiments. Data are expressed as the percentage of values of control (mean \pm SEM). $* p<0.05 ; * * p<0.01$ versus control; \# ${ }^{\#}<0.01$ versus OGD. HBMEC, human brain microvascular endothelial cell.

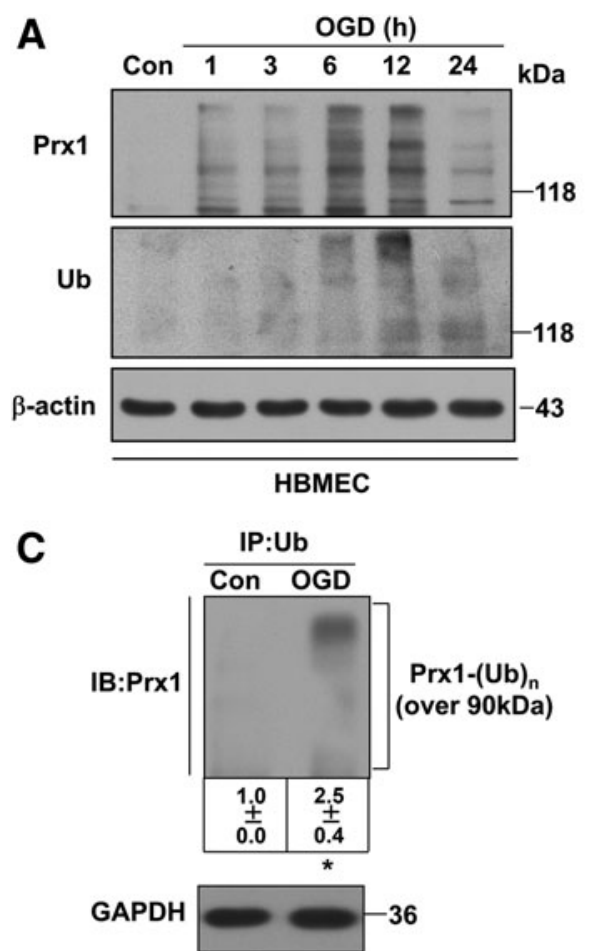

B
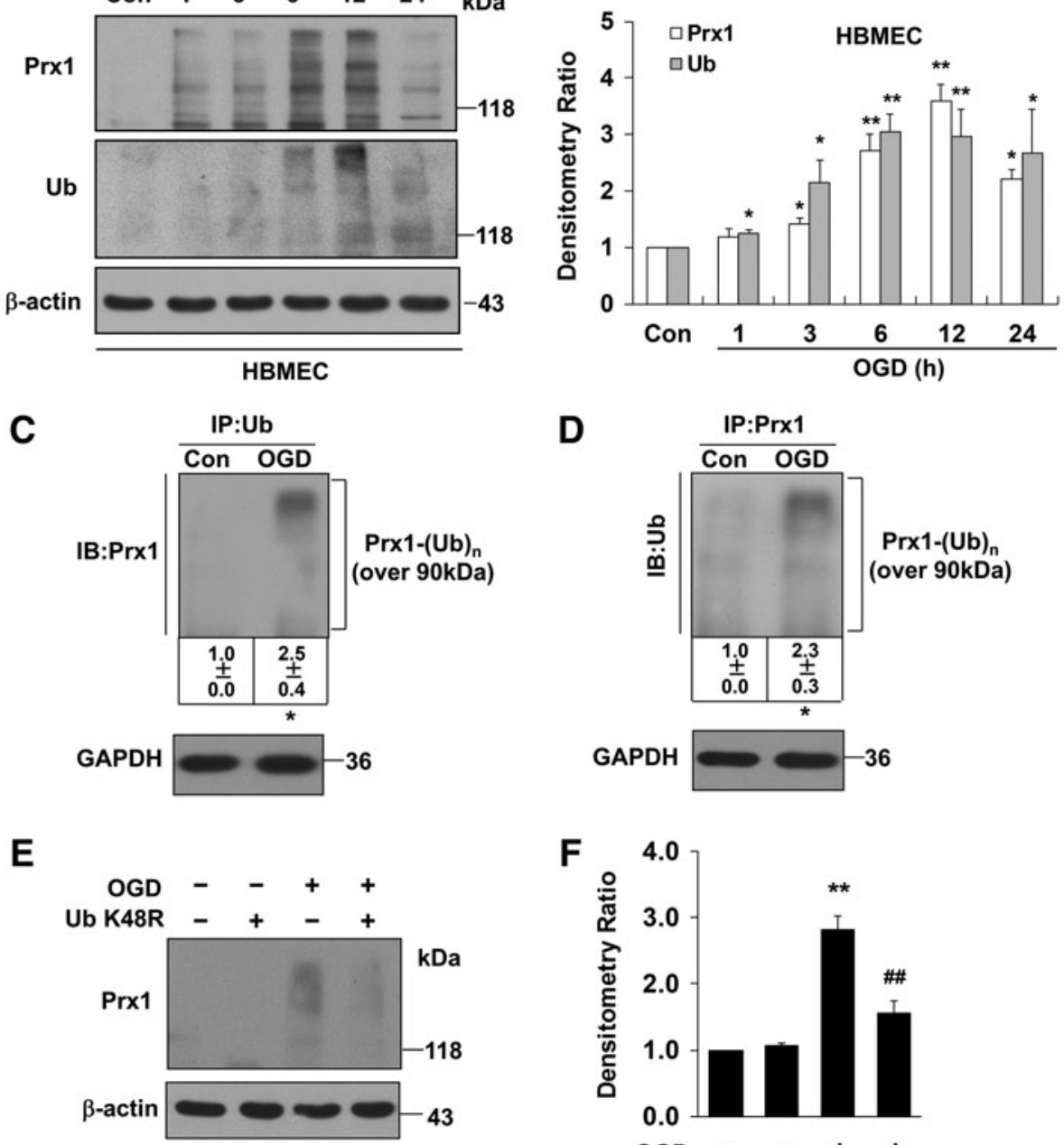

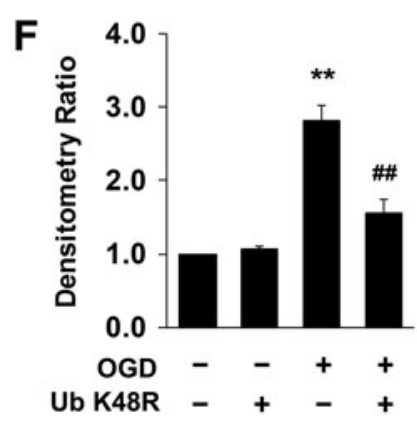

demonstrated that the E6AP/nitrotyrosine interaction in OGD-treated endothelial cells was significantly increased. Consistently, OGD-induced tyrosine nitration of E6AP was further confirmed by the immunoprecipitation of nitrotyrosine followed by immunoblotting with an anti-E6AP antibody (Fig. 6J). In addition, Prx1 immunoprecipitates from the lysates were probed with anti-nitrotyrosine antibody demonstrating that OGD did not induce Prx1 protein co-immunoprecipitate with nitrotyrosine (Supplementary Fig. S7). Melatonin blunted the ubiquitination of Prx1 in OGD-treated cells (Supplementary Fig. S8), suggesting that nitrosative stress induced Prx1 ubiquitination during OGD.

\section{E6AP activation contributes to Prx1 stress response in brain microvessels after transient middle cerebral artery occlusion in mice}

Since there are limited in vivo data on the degradation of Prx 1 by ubiquitin ligases in ischemic brain, we used a mouse transient middle cerebral artery occlusion (tMCAO) model for further study. The immunoreactivity for E6AP was observed predominantly in the ipsilateral brain microvessel endothelium $6 \mathrm{~h}$ after tMCAO (Fig. 7A-e), accompanied by increased Prx1 immunoreactivity (Fig. 7A-d). A representa- tive Z-stack image is shown in Figure 7B. However, after $24 \mathrm{~h}$, Prx1 was downregulated where E6AP remained upregulated in the brain microvessel endothelium (Fig. 7A, g-i). Ubiquitination of Prx 1 was elevated significantly in the brain microvessels $6 \mathrm{~h}$ after MCAO (Fig. 7C, D), whereas Prx 1 staining was observed in microvessels of sham-operated animals where ubiquitin staining was absent. To further determine E6AP as a key modulator in nitrosative stress-mediated cerebrovascular damage in vivo, we stereotaxically delivered a lentivirus carrying mouse $\mathrm{sh} E 6 A P$ into the ventricle in mice 2 weeks before MCAO, followed by ischemia and $24 \mathrm{~h}$ reperfusion. Western blot analysis showed that lentivirus-mediated cerebral E6AP knockdown reduced cerebrovascular damage, which was demonstrated by preventing ischemiainduced dephosphorylation of prosurvival kinases and tight junction proteins breakdown (Fig. 7E-G).

\section{Lentiviral-Prx1 brain transduction protects against neurovascular damage in $\mathrm{IMCAO}$ mice}

Two weeks after the cerebroventricular injection of a lentiviral-GFP vector encoding mouse Prxl (LV-Prxl), there was efficient and sustained GFP fluorescence in the brain ventricles (Fig. 8A), cortex (Fig. 8B), hippocampus, and 
A

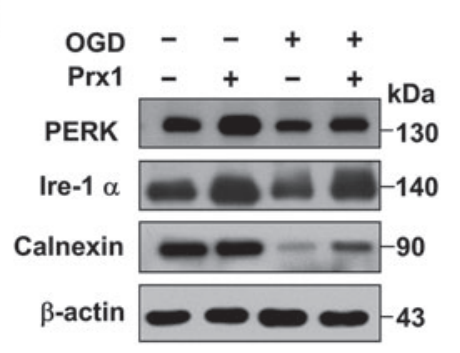

B
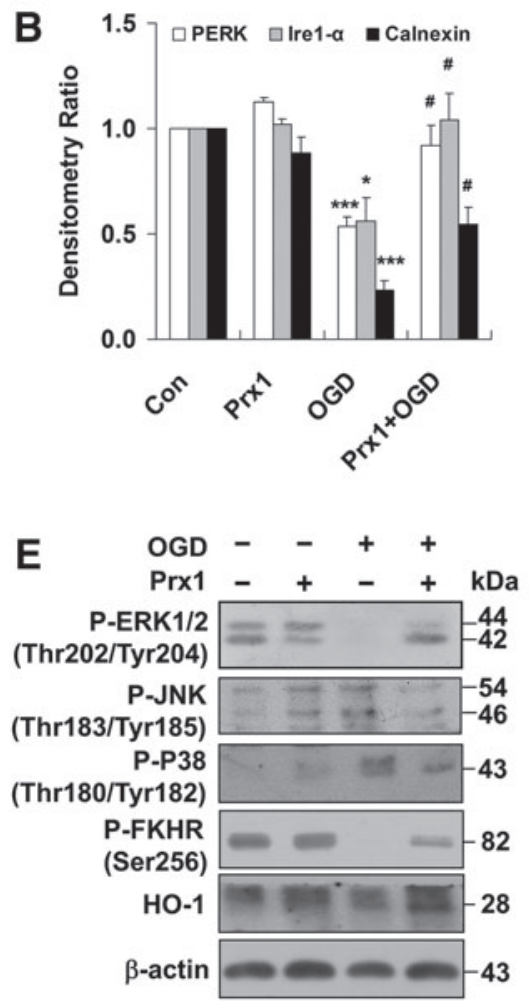

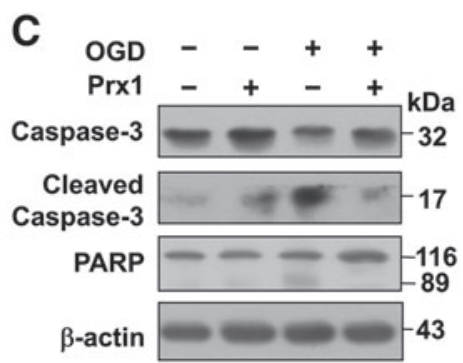

G
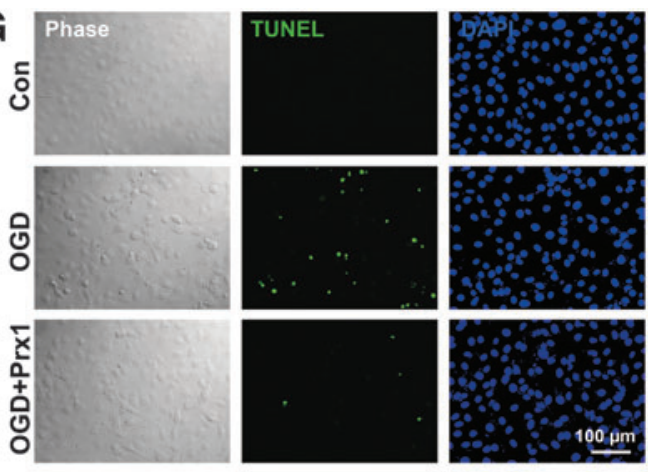

H

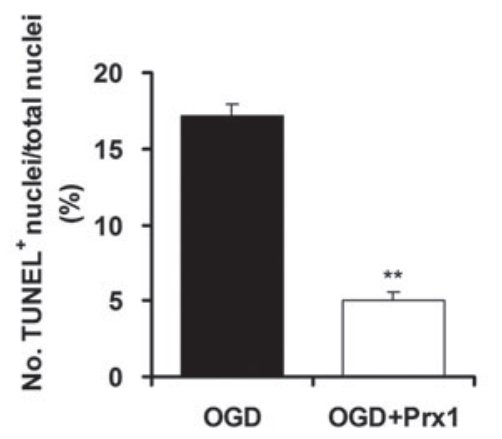

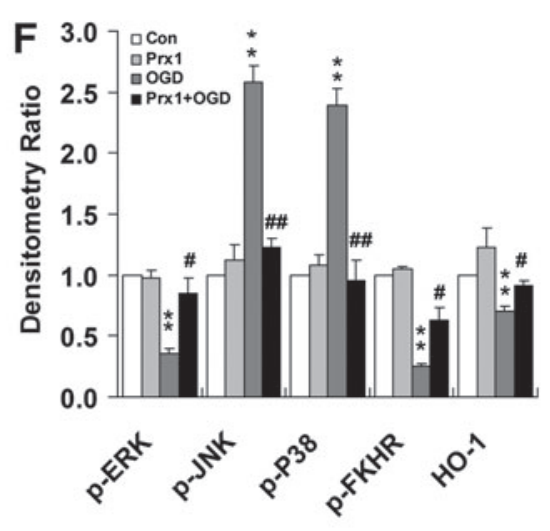

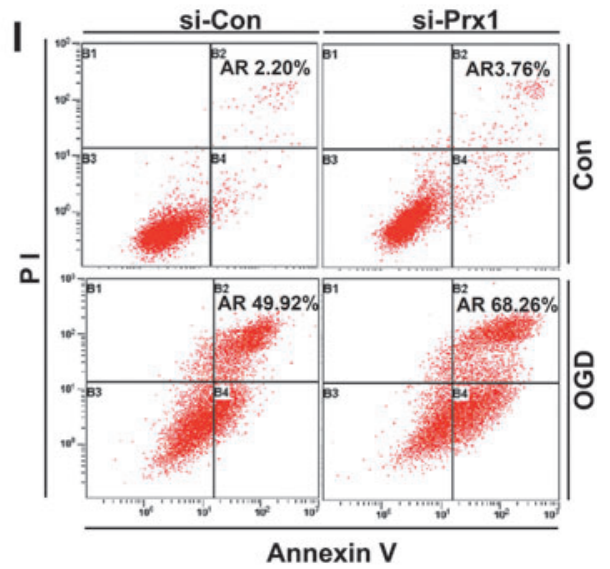

FIG. 4. Role of Prx1 in the OGD-induced apoptotic cascade in endothelial cells. (A) The effects of Prx1 on OGDinduced ER stress signaling were determined by immunoblotting. (B) Densitometry of Western blots for PERK, Ire-1 $\alpha$, and calnexin levels $6 \mathrm{~h}$ after OGD, with or without Prxl transfection. Data are expressed as densitometry ratio of control (mean \pm SEM). $* p<0.05 ; * * * p<0.001$ versus control; ${ }^{*} p<0.05$ versus OGD. (C) The effects of Prx 1 overexpression on OGDinduced caspase-3 and PARP levels were evaluated by immunoblotting. EA.hy926 cells were cultured and transfected with plasmid DNA encoding Prxl or an empty plasmid using Attractene. (D) The quantification data for blots are shown in (C). Data are expressed as densitometry ratio of control (mean \pm SEM). ${ }^{* *} p<0.01$ versus control; ${ }^{\#} p<0.05 ;{ }^{\# \#} p<0.01$ versus OGD. (E) The effects of Prx1 overexpression on OGD-induced protein levels were evaluated by immunoblotting. Cells were transfected with Prxl plasmid followed by $6 \mathrm{~h}$ of OGD or control stimulation. Cell lysates were prepared and resolved by SDSPAGE. The proteins were immunoblotted with antibodies against phospho-ERK, phospho-JNK, phospho-P38, phospho-FKHR (Ser256), and HO-1. (F) Quantitative analysis of protein levels for (E) was performed by densitometry. Data are expressed as densitometry ratio of control (mean \pm SEM). ${ }^{* *} p<0.01$ versus control; ${ }^{\#} p<0.05 ;{ }^{\# \#} p<0.01$ versus $\mathrm{OGD}$. (G) Changes in apoptosis $6 \mathrm{~h}$ after OGD were detected using the TUNEL assay. Double staining was performed for TUNEL (green) and DAPI (blue). The representative images show the increased percentage of TUNEL-positive apoptotic endothelial nuclei (green fluorescence) $6 \mathrm{~h}$ after OGD. Scale bar $=100 \mu \mathrm{m}$. (H) Quantification of TUNEL-positive apoptotic endothelial cells with or without Prxl transfection. Apoptosis was dramatically reduced following the overexpression of the Prxl gene in endothelial cells after OGD. $* * p<0.01$ versus OGD group. (I) Representative flow cytometric dot plots of apoptotic cells after OGD with or without PrxlsiRNA transfection. Cultured EA.hy926 cells were stimulated for $6 \mathrm{~h}$ with OGD with or without $\operatorname{Prx} 1$ siRNA transfection. Cells were double-stained with Annexin-V and PI and analyzed by FACS. Immunoblots are representative of three independent experiments. $\beta$-Actin was used as the loading control. DAPI, 4',6-diamidino-2-phenylindole; ER, endoplasmic reticulum; HO-1, heme oxygenase-1; JNK, c-Jun N-terminal kinase; PARP, poly ADP-ribose polymerase; siRNA, small interfering RNA; TUNEL, terminal deoxynucleotidyl transferase dUTP nick end labeling; PI, propidium iodide. To see this illustration in color, the reader is referred to the web version of this article at www.liebertpub.com/ars 

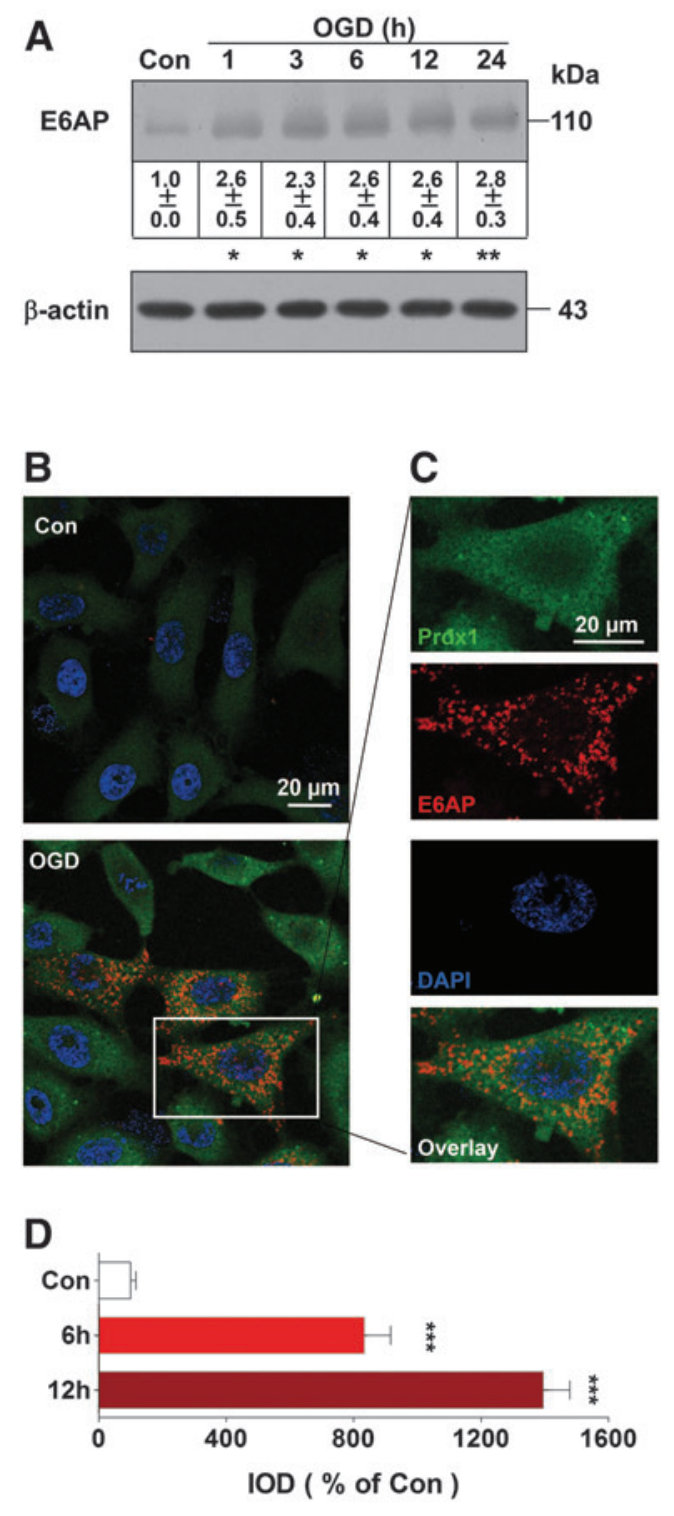
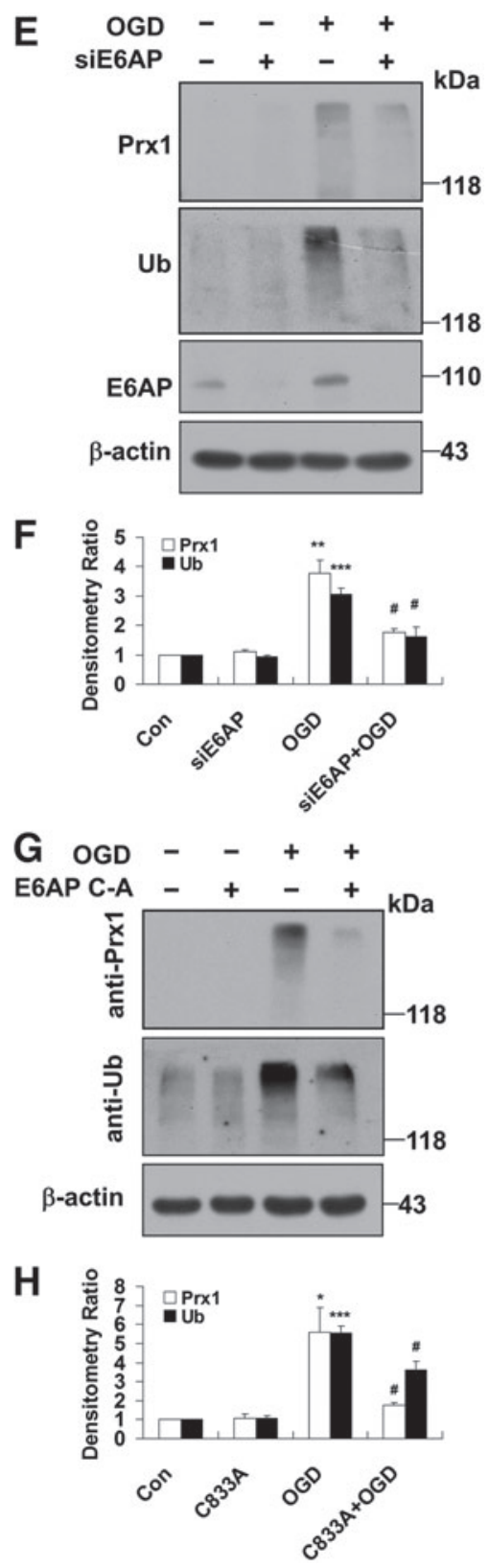

FIG. 5. E6AP activation contributes to the Prx1 stress response after OGD. (A) The representative image showing E6AP activation at the indicated time points after OGD treatment. Data are expressed as densitometry ratio of control (mean \pm SEM). $* p<0.05 ; * *<0.01$ versus control. (B) Immunocytochemical analysis of E6AP expression after OGD treatment. Laser confocal microscopy demonstrated low to undetectable levels of E6AP in control cells. (C) Highermagnification image of endothelial staining from the insets of (B). DAPI counterstaining indicates nuclear localization (blue). Scale bar $=20 \mu \mathrm{m}$. (D) Quantification of Prx1 immunofluorescence expressed as integrated optical density (IOD). *** $p<0.001$ versus control. (E) E6AP knockdown reduced the OGD-induced formation of multiubiquitinylated proteins. Cells were submitted to E6AP knockdown and OGD or the control condition for $6 \mathrm{~h}$. Cell lysates were prepared and resolved by SDS-PAGE. The proteins were immunoblotted with antibodies against Prx1, E6AP, and ubiquitin. (F) Quantitative analyses for $(\mathbf{E})$ are shown in the bar graph as densitometry ratio of control (mean \pm SEM). ${ }^{* *} p<0.01$; $* * * p<0.001$ versus control; ${ }^{\#} p<0.05$ versus OGD. (G) The $\mathrm{E} 6 \mathrm{AP}_{C-A}$ mutant decreased OGD-induced Prx1 ubiquitination in endothelial cells. EA.hy926 cells were cultured and transfected with plasmid DNA encoding the E6AP $P_{C-A}$ mutant or an empty plasmid using Attractene. (H) Quantitative analysis of protein levels for (G) was performed by densitometry. Data are expressed as densitometry ratio of control (mean \pm SEM). ${ }^{*} p<0.05$; $* * * p<0.001$ versus control; ${ }^{\#} p<0.05$ versus OGD. Immunodetection of $\beta$-actin was used as a loading control. Immunoblots are representative of three independent experiments. E6AP, E6-associated protein. To see this illustration in color, the reader is referred to the web version of this article at www.liebertpub.com/ars 


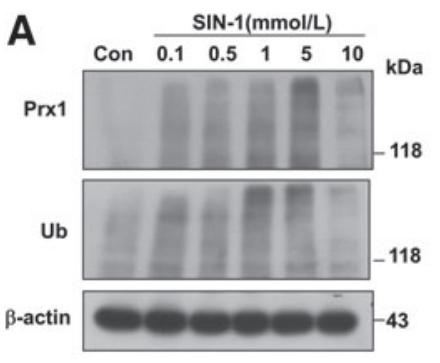

E
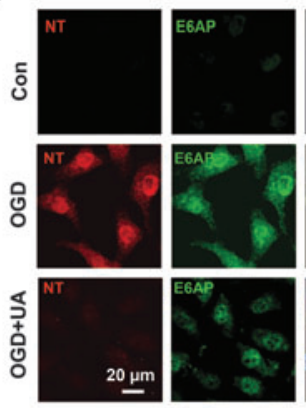

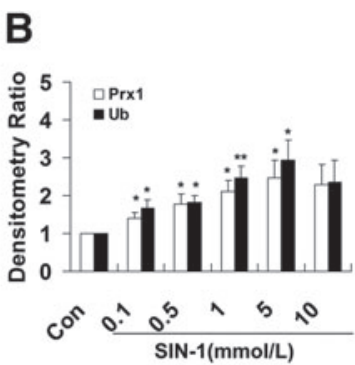

$\mathbf{F}$
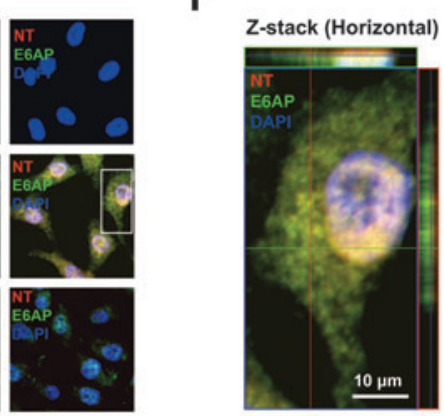
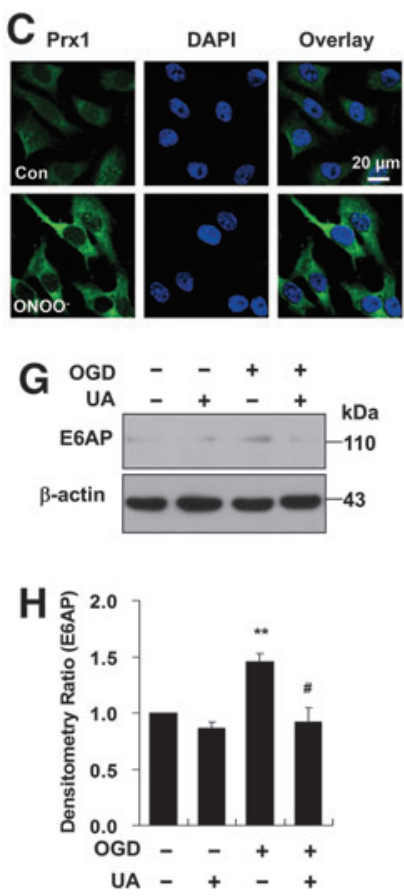
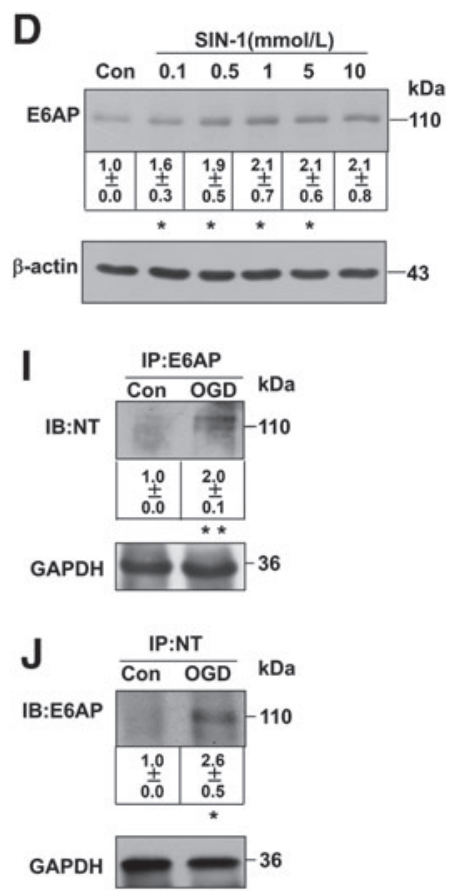

FIG. 6. Nitrosative stress is associated with ubiquitination of Prx1 in endothelial cells. (A) The ubiquitination of Prx1 after SIN-1 stimulation in endothelial cells. The blots were labeled with anti-Prx1 or anti-ubiquitin antibody and visualized with the ECL system. Molecular sizes are indicated on the right. (B) The SIN-1-induced changes in polyubiquitinated Prx1 were quantified and shown in the bar graph as densitometry ratio of control (mean \pm SEM). ${ }^{*} p<0.05 ;{ }^{* *} p<0.01$ versus control. (C) Immunocytochemical analysis of Prx1 level after $\mathrm{ONOO}^{-}$treatment by laser confocal microscopy. DAPI counterstaining indicates nuclear localization (blue). (D) The effects of SIN-1 treatment on E6AP protein levels were examined in cell lysates of endothelial cells. EA.hy926 endothelial cells were cultured with or without SIN-1 treatment for $6 \mathrm{~h}$ at the indicated concentrations. Immunoblots are representative of three independent experiments (mean \pm SEM). ${ }^{*} p<0.05$ versus control. (E) Fluorescence immunocytochemical staining of E6AP and nitrotyrosine $6 \mathrm{~h}$ after OGD in endothelial cells with or without $0.5 \mathrm{~m} M$ uric acid treatment. DAPI counterstaining indicates nuclear localization (blue). NT, nitrotyrosine; UA, uric acid. (F) Higher-magnification image of endothelial staining from the insets is shown in (E). (G) Effect of uric acid on E6AP expression in endothelial cells following OGD. Immunodetection of $\beta$-actin was used as a loading control. (H) Quantification of E6AP protein levels was performed using densitometric analysis of the immunoblots in $(\mathbf{G})$. Immunoblots are representative of three independent experiments. Data are expressed as the percentage of values of control (mean \pm SEM). ${ }^{* *} p<0.01$ versus control; \# $p<0.05$ versus OGD. (I) Immunoprecipitation of E6AP from cell lysates of OGD-treated endothelial cells followed by blotting with an anti-nitrotyrosine antibody. $* * p<0.01$ versus control. (J) The OGD-induced nitration of E6AP was detected by the immunoprecipitation of nitrotyrosine followed by immunoblotting with an anti-E6AP antibody. Immunoblots are representative of three independent experiments (mean $\pm \mathrm{SEM}$ ). ${ }^{*} p<0.05$ versus control. SIN-1, 3-morpholinosydnonimine. To see this illustration in color, the reader is referred to the web version of this article at www.liebertpub.com/ars

striatum (Supplementary Figs. S9 and S10). Staining of brain sections from lentiviral-GFP-injected mice with a neuronal nuclear marker (NeuN) (Fig. 8B-d) and an endothelial marker CD31 (Fig. 8B-e, f) indicates that the vector successfully transduced cells in the brain. Although the lentiviral vectors might directly diffused into the brain parenchyma, the present data indicate that lentiviral vectors in cerebral ventricular can diffuse along the neurovascular scaffold. Immunohistochemical analysis of ipsilateral sections revealed stronger GFP fluorescence in $\mathrm{TCAO}$ mice that formed a continuous interendothelial staining pattern that colocalized with CD31 (Fig. 8C, D).

The protective effects of Prx1 against ischemia-induced neurological and functional deficit were evaluated by the rotarod test and neurological score measurements. The neurological scores were decreased significantly, and rotarod time was increased in LV-Prxl-treated mice $24 \mathrm{~h}$ after tMCAO (Fig. 9A) and the infarct area was reduced accordingly (Fig. 9B). The breakdown products of spectrin and calcineurin were increased after tMCAO (Fig. 9C, D), coincident with BBB leakage (Fig. 9E, F). LV-Prxl treatment blocked the degradation of tight junction proteins zonula occludens-1 (ZO-1) and claudin5 (Fig. 9C, D, and G) and significantly reduced BBB leakage (Fig. 9E, F). LV-Prxl transduction reduced the $\mathrm{O}_{2}{ }^{\bullet-}$ level assessed from dihydroethidium staining in the penumbra region of mice $24 \mathrm{~h}$ after tMCAO (Fig. 9H, I).

\section{Schematic illustration of the mechanisms by which nitrosative stress induces Prx1 ubiquitination during ischemic insult in endothelial cells}

We hypothesize that ischemia-induced nitrosative stress causes an early increase in Prx 1 production during the adaptive phase, whereas excessive or prolonged ischemia activates E6AP E3 ubiquitin ligase, which targets Prx1 for ubiquitination and degradation during the late phase, thereby degrading the Prx1-related antioxidant defense pathway and 
FIG. 7. E6AP activation is associated with Prx1 ubiquitination in brain microvessels of cerebral ischemia mice. (A) Double immunohistochemical staining for Prx1 and E6AP in the penumbra after tMCAO. Fluorescence staining for Prx1 (green) and E6AP (red) was performed in ipsilateral brain regions 6 and $24 \mathrm{~h}$ after brain ischemic injury in mice. (B) The orthogonal projections onto the $x-z$ (upper) and $y-z$ (right) planes are shown to confirm the colocalization of Prx1 and E6AP throughout the microvessels shown in (A). (C) Fluorescence immunohistochemical staining of Prx 1 and ubiquitin in brain microvessels. Anti-ubiquitin (red) and Prx1 (green) staining was performed $6 \mathrm{~h}$ after tMCAO in mice. (D) Higher-magnification image of endothelial staining from the insets is shown in (C). Each image shown is representative of five independent mice. (E) The effect of E6AP knockdown on neurovascular damage after brain ischemia in mice. The lentivirus E6AP shRNA knockdown was used to silence E6AP mRNA. The protein extracts from penumbra brain region of mice were processed for Western blotting to detect ZO-1, Occludin, and phosphorylated AKT, ERK, FHHR. (F, G) Quantitative analysis of protein levels in $(\mathbf{E})$ was performed by densitometry. Densitometry values were normalized to the average of all sham values (mean \pm SEM, $n=6) . * p<0.05 ; * * p<0.01$ versus sham mice; ${ }^{*} p<0.05$; ${ }^{\# \#} p<0.01 \quad$ versus vehicle-treated mice. Immunoblotting with an anti- $\beta$ actin antibody demonstrated equal protein loading in each lane. $\mathrm{MCAO}$, transient middle cerebral artery occlusion; ZO-1, zonula occludens-1; shRNA, short hairpin RNA. To see this illustration in color, the reader is referred to the web version of this article at www.liebertpub.com/ars
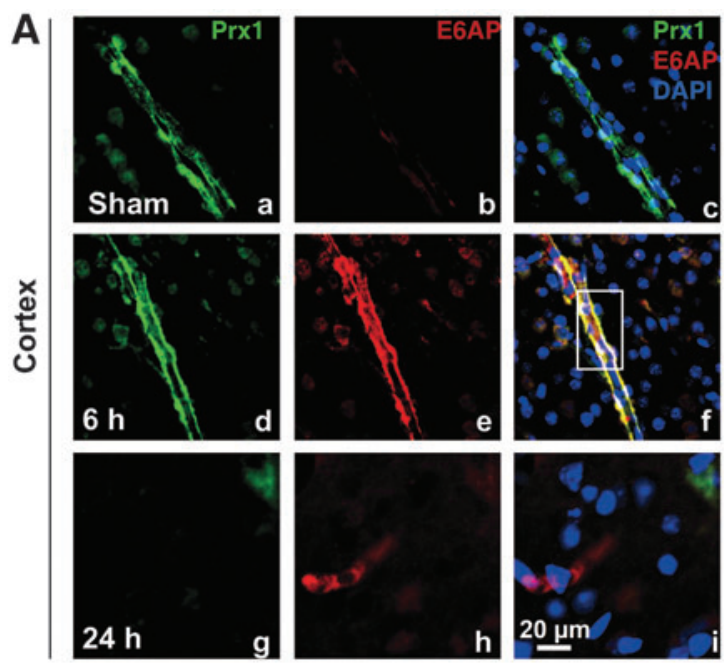

B Z-stack (Horizontal)
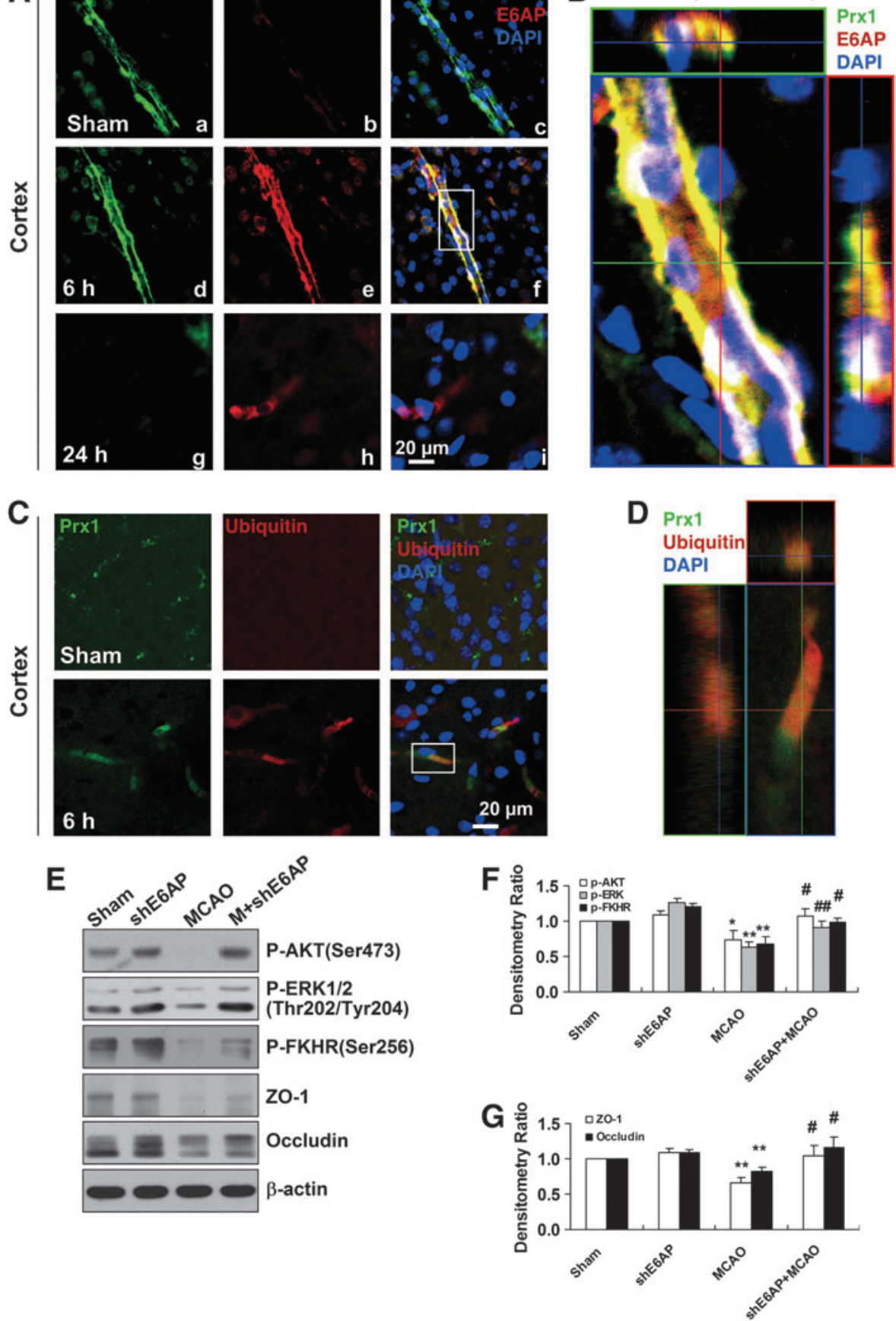

rendering the endothelial cells in the microvessels susceptible to ischemic damage (Fig. 10).

\section{Discussion}

The present study demonstrates that in endothelial cells OGD treatment leads to oxidative and nitrosative stress that engage an early increase in Prx1 production and an antioxidant response. However, more prolonged or severe ischemia-mediated nitrosative stress ubiquitinates Prx1 by the activation of E6AP ligase, thereby degrading this antioxidant defense pathway. The translational studies in mice after MCAO demonstrated that neurovascular protection was coordinated by active Prx1.
Prx 1 initiates the antioxidant response by scavenging free radicals formed in response to a diverse array of cellular stresses $(40,44)$. Upregulation of Prx1 may be secondary to the activation of NF-E2-related factor 2 (Nrf2) (24), as Prx1 promoter has two antioxidant response elements that are putative binding sites for Nrf2. Indeed, we recently demonstrated that Nrf2 signaling coordinates the defense against ischemia/nitrosative stress in endothelial cells (49).

The ubiquitin-proteasome system is important for protein degradation in eukaryotic cells $(19,42)$. Unexpectedly, ubiquitin was not highly expressed in control endothelial cells, but high-molecular-weight Prx1-polyubiquitin ladders were observed after OGD or SIN-1 treatment. The aggregation of 

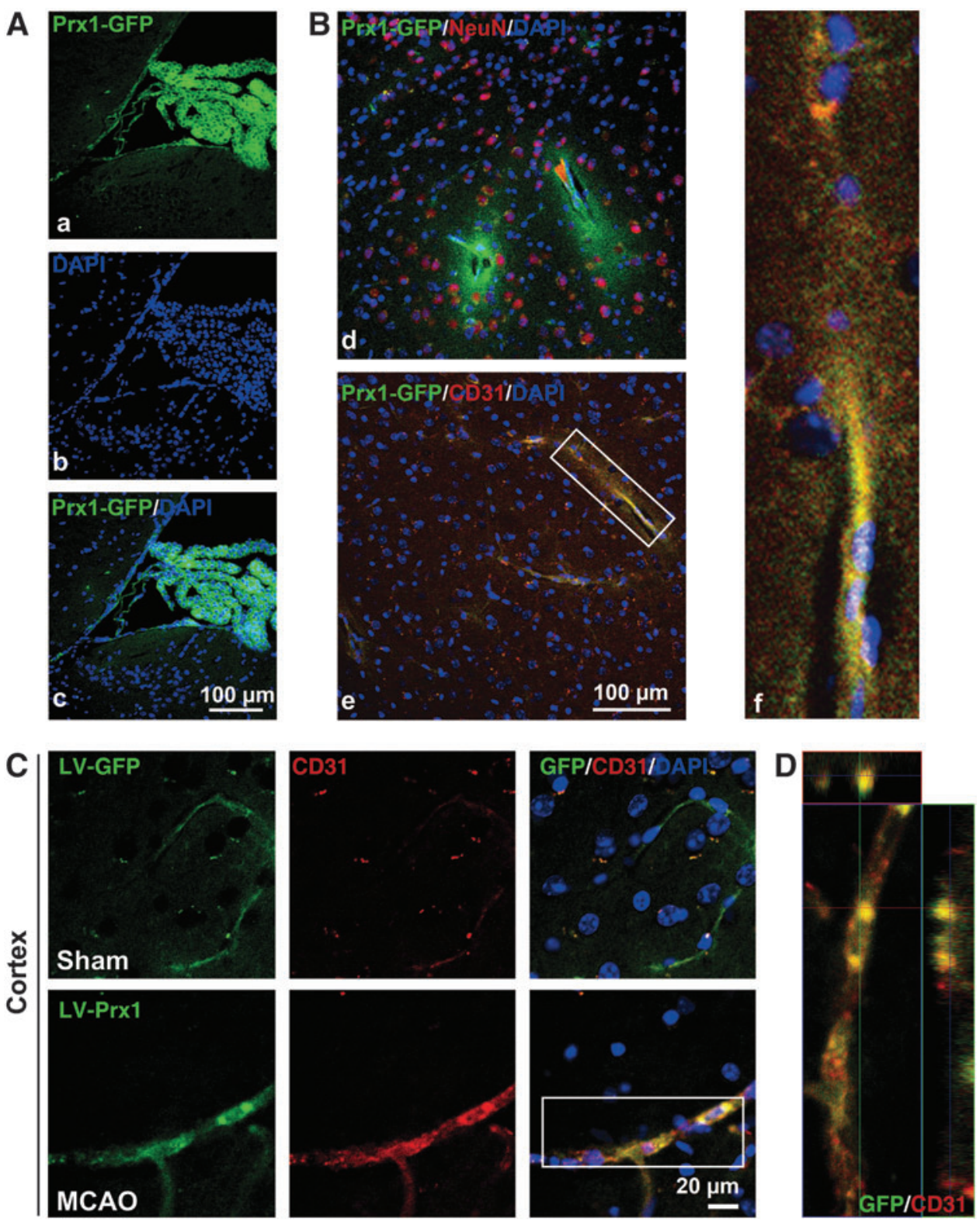

FIG. 8. The brain microvessels are the primary cell type transduced by the LV$G F P$ vector in the ipsilateral side of tMCAO mice. (A) The distribution of LVGFP-Prx1 in the choroid plexus of the mouse brain 2 weeks after intracerebroventricular injection. Images demonstrate successful LVGFP-Prxl transduction in choroid plexus cells. (B) The immunohistochemical localization of NeuN-labeled cells (red) in (d) and CD31marked cells (red) in (e) were examined in brain cortex of mice. The inset (f) showing magnified images from (B-e) demonstrates the localization of GFP-Prx1 in the microvessels of the brain. (C) Representative immunostaining demonstrates that CD31 (red) colocalized with GFP-Prx1 on the ipsilateral side of the brain cortex $24 \mathrm{~h}$ after MCAO. (D) Representative Z-stack images shown in (C). Each image shown is representative of five independently injected mice. NeuN, neuronal nuclear marker. To see this illustration in color, the reader is referred to the web version of this article at www.liebertpub.com/ars ubiquitinylated Prx 1 proteins in endothelial cells after OGD reflects an imbalance between the amount of toxic unfolded proteins and the capacity of the proteasomal system to eliminate them, which may culminate in ER stress. Consistent with our in vitro data, there was an increased ubiquitination of Prx 1 in brain microvessels of mice following MCAO that was associated with endothelial/microvessel injury. The formation of ubiquitin-protein conjugates (ubi-proteins) may mediate ischemic cell death $(19,51)$. A time-dependent increase in E6AP after OGD induced Prx1 ubiquitination (33). The upregulation and colocalization of E6AP with Prx1 after OGD was blunted by inhibition of nitrosative stress with uric acid or FeTPPS.

Our results identify E6AP as the E3 ligase that targets Prx1 for degradation in the later phases of OGD. Accordingly, we tested the functional relevance of this pathway in protecting the $\mathrm{BBB}$ of mice during $\mathrm{tMCAO}$. Brain ischemia increased E6AP expression in microvessels of the penumbra region.
Nitrosative stress from the reaction of NO generated by NO synthases in damaged brain cells and $\mathrm{O}_{2}{ }^{\bullet-}$ generated during ischemia underlays the ischemic cerebral cell death $(17,48)$. We speculate from our endothelial cell model that ischemic nitrosative stress induced the overproduction of brain microvascular E6AP. Indeed, the computational predictor evaluated 7 potential tyrosine nitration sites of E6AP with high score (Supplementary Fig. S11). Additionally, S-nitrosylation has been shown to modify the function of many proteins $(1,32)$. Therefore, it will also be important to further characterize the protein $S$-nitrosylation of thiol and amine groups during ischemia in the future.

Our finding that inhibition of nitrosative stress and redirection of E6AP restored Prx1 signaling in endothelial cells defines a new vasoprotective mechanism against the damaging consequences of ischemia. This was exemplified by the demonstration that Prx1 overexpression in the intact brain blocked tMCAO-induced neurovascular damage, attenuated 
A

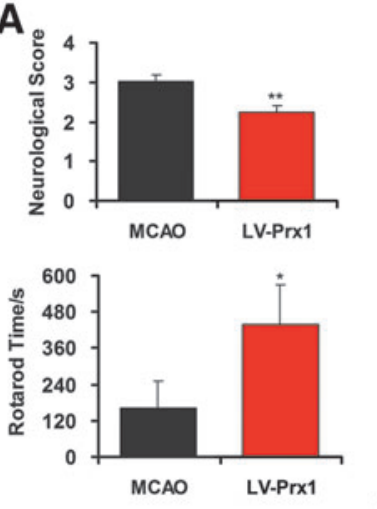

C

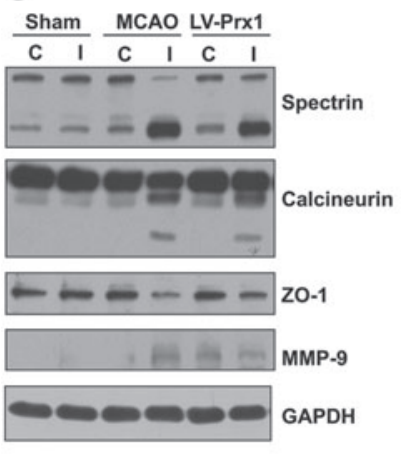

H

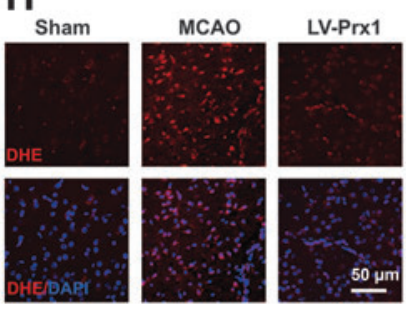

B
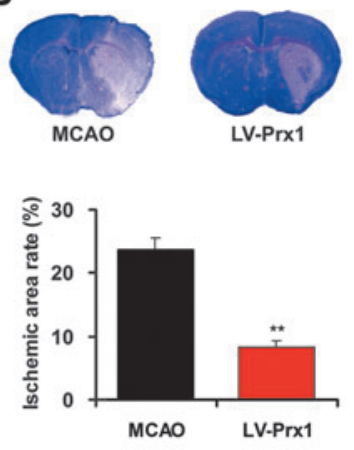

E
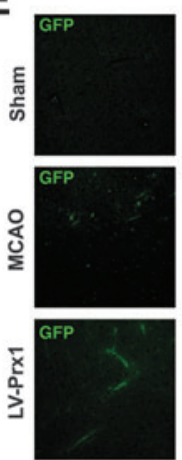

70

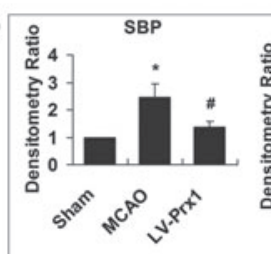

CBP
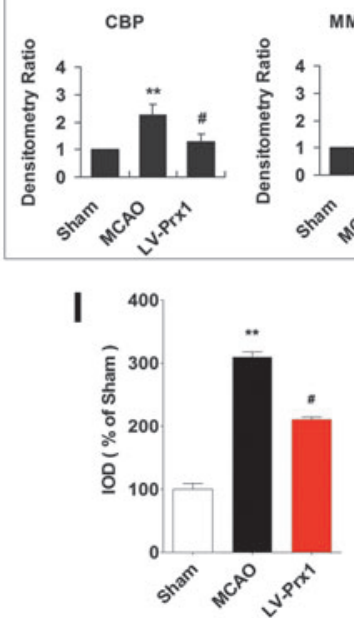

G
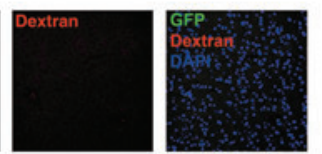

$\mathbf{F}$

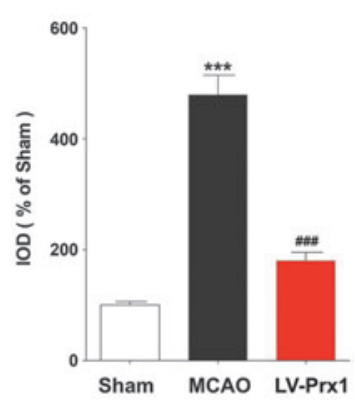

FIG. 9. Lentiviral-mediated delivery of Prx1 protects against neurovascular protection in tMCAO mice. (A) Lentiviral-mediated delivery of Prx 1 improved neurological functional recovery after focal ischemia. The neurological scores (upper) and rotarod test (lower) were examined. The data are expressed as the percentage of the values observed in vehicletreated animals (mean $\pm \mathrm{SEM}, n=10$ ). $* p<0.05 ; * *<0.01$ versus vehicle-treated mice. (B) LV-Prxl transduction reduced the infarct area of mice $24 \mathrm{~h}$ after tMCAO. The mice were subjected to $45 \mathrm{~min}$ of MCAO, and the infarct area was quantified $24 \mathrm{~h}$ later in cresyl violet-stained brain sections. The data are expressed as the percentage of the infarct area/total area of each brain section (mean \pm SEM, $n=10$ ). ${ }^{* *} p<0.01$ versus vehicle-treated mice. (C) The effect of LV-Prxl on neurovascular damage after brain ischemia. The proteins from penumbra brain region of mice were immunoblotted with antibodies against spectrin, calcineurin, ZO-1, and MMP-9, which are indicative antibodies for neurovascular damage. C, contralateral; I, ipsilateral. (D) The quantitative analyses are shown in the bar graph as the percentage of values of sham-operated animals (mean \pm SEM, $n=4) .{ }^{*} p<0.05 ; * * p<0.01$ versus sham mice; ${ }^{\#}<0.05$ versus vehicle-treated mice. Immunoblotting with an anti- $\beta$-actin antibody demonstrated equal protein loading in each lane. SBP, spectrin breakdown products; CBP, calcineurin breakdown products. (E) LV-Prxl transduction attenuated BBB disruption 24h after tMCAO. Mice were intravenously injected with Texas red-dextran in saline and perfused 120 min later. Ex vivo dextran labeling (red fluorescence) indicated extensive BBB permeability around disrupted brain microvessels in tMCAO mice. (F) Quantification of Texas red-dextran immunofluorescence expressed as integrated optical density (IOD). ${ }^{* * *} p<0.001$ versus sham; ${ }^{\# \#} p<0.001$ versus vehicle-treated mice. (G) Effect of LV-Prx1 transduction on the degradation of claudin5. (a) Immunostaining with anti-claudin5 (red fluorescence) antibody showed brain ischemia-induced claudin5 degradation (c, d) in the microvessels $24 \mathrm{~h}$ after tMCAO. LV-Prx 1 transduction reduced the degradation of claudin $5(\mathbf{e}-\mathbf{g})$ in the microvessels $24 \mathrm{~h}$ after tMCAO. Higher-magnification images of microvessel staining (b, d, $\mathbf{g}$ ) from the insets of (a, c, f), respectively. (H) The effect of Prxl transduction on $\mathrm{O}_{2}{ }^{\bullet-}$ levels, as determined by in situ dihydroethidium staining. LV-Prxl transduction reduced the $\mathrm{O}_{2}{ }^{\bullet-}$ level in the penumbra region compared to vehicle. Each image shown is representative of five independently injected mice. DHE, dihydroethidium. (I) The quantitative analyses of dihydroethidium immunofluorescence are shown in the bar graph. $* * p<0.01$ versus sham; ${ }^{\#}<<0.05$ versus vehicle-treated mice. $\mathrm{BBB}$, blood-brain barrier; $\mathrm{O}_{2}{ }^{--}$, superoxide. To see this illustration in color, the reader is referred to the web version of this article at www.liebertpub.com/ars 


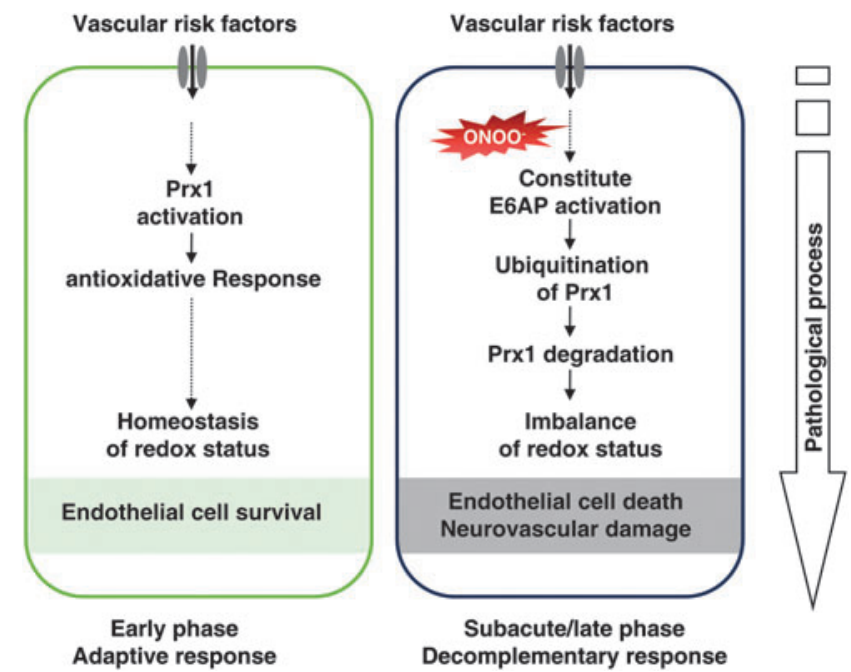

FIG. 10. Schematic illustration of the mechanisms by which nitrosative stress induces Prx1 ubiquitination in endothelial cells during ischemic insult via E6AP activation. To see this illustration in color, the reader is referred to the web version of this article at www.liebertpub.com/ars

BBB damage, preserved the ZO-1, and prevented the activation of metalloproteinases (MMPs). This is similar to the reports that Prx1 was required also for neurovascular cell survival during exposure to pathogenic proteins associated with brain ischemia or with amyloid- $\beta$ expression in neurons (30). These results are consistent with the finding that Prxl-deficient mice suffer embryonic lethality because they lack essential antioxidant function $(25,34,39)$. Although the neurovascular cells might be a critical issue during the earlier phase of brain ischemia, the functional coupling and collaborations among the capillaries, glia, and neurons of the brain should be taken into consideration $(9,37)$. For instance, recent studies highlight that pericyte loss causes BBB breakdown and neurodegeneration $(2,36)$. Therefore, how Prx1-mediated vascular protection contributed to the neuronal survival in the present study, however, is a topic for further investigation. Prx 1 protein levels can prevent excessive ROS accumulation by interaction with thioredoxin to detoxify hydrogen peroxide $\left(\mathrm{H}_{2} \mathrm{O}_{2}\right), \mathrm{ONOO}^{-}$, and a range of organic hydroperoxides (34). We found further that $\mathrm{LV}$ transduction reduced $\mathrm{O}_{2}{ }^{\bullet-}$ formation in the ipsilateral region of the ischemia brain, which might be a consequence of ERK and FKHR activation by Prx1. Indeed, Prxs participate in a very wide range of reactions, including neuronal differentiation, cell signaling, molecular chaperoning, and mitochondrial function, in both catalytic-dependent and catalytic-independent manners and can interact with JNK, c-Abl, and apoptosis signal-regulating kinase 1 (ASK1) in a redox-regulated manner $(11,14,21,23)$. Here, ipsilateral sections showed stronger GFP fluorescence in cerebral vessels of tMCAO mice, it might due to the changes of structural integrity in ischemic region, where dividing cell also largely accumulated $(12,20)$.

In summary, our studies identify an intracellular link between nitrosative stress and Prx1 signaling in endothelial cells following ischemia-like injury. Our description of an early ischemia-induced activation of beneficial Prx1 generation followed by subsequent inactivation represents a pre- viously undescribed, nitrosative stress-dependent process mediated by E6AP-dependent Prx1 ubiquitination and subsequent endothelial barrier damage. Since Prx 1 protected against oxidative stress in endothelial cells to reduce injury after ischemia, both in vitro- and in vivo-specific inducers of the Prx1 pathway, or mechanisms to prevent its degradation, may be targeted for therapeutic benefit in neurovascular disorders.

\section{Materials and Methods}

\section{Reagents}

Dulbecco's modified Eagle's medium (DMEM) and fetal bovine serum were purchased from Gibco. Alexa Fluor 488conjugated anti-rabbit IgG and Alexa Fluor 594-conjugated anti-mouse IgG were obtained from Invitrogen. Uric acid was obtained from Wako. 5,10,15,20-Tetrakis-[4-sulfonatophenyl]porphyrinato-iron[III] (FeTPPS; Calbiochem) was used as a specific $\mathrm{ONOO}^{-}$decomposition catalyst. Unless otherwise stated, all reagents and chemicals were obtained from Sigma-Aldrich.

\section{OGD exposure and experimental treatments of cell cultures}

EA.hy926 cells $(16,43)$, HBMECs, and mouse brain microvascular endothelial cells (bEnd.3) were used for Western blot or immunocytochemistry in the present study. Briefly, in the oxygen and glucose deprivation phase, the culture medium was replaced and washed with glucose-free Hank's balanced salt solution, after which the cultures were placed in an airtight experimental hypoxia chamber (Billups-Rothenberg) containing a gas mixture comprising $95 \% \mathrm{~N}_{2}$ and $5 \% \mathrm{CO}_{2}$. To mimic an ischemia-like condition in vitro, cell cultures were exposed to OGD for $1,3,6,12$, and $24 \mathrm{~h}$. Cells without OGD served as controls.

\section{Two-dimensional gel electrophoresis}

Approximately $450 \mu \mathrm{g}$ of protein was resuspended in a rehydration solution [8 $M$ Urea, 2\% CHAPS, $20 \mathrm{~m} M$ DTT, $0.2 \%$ Biolyte ( $\mathrm{pH}$ range $3-10$ ), and $0.2 \%$ Bromphenol blue] and applied to $17-\mathrm{cm} \mathrm{pH} \mathrm{3-10} \mathrm{nonlinear} \mathrm{gradient} \mathrm{immobiline}$ strips for isoelectric focusing. Isoelectric focusing was performed using Protean IEF Cell (Bio-Rad), and the proteins in the IPG strips were subsequently placed on a $12 \%$ uniform sodium dodecyl sulfate (SDS)-polyacrylamide gel. The gels were silver stained and scanned with an Image Scanner in transmission mode, after which image analysis was conducted with two-dimensional PDquest (Bio-Rad). The twodimensional gel electrophoresis was repeated three times using independently grown cultures.

\section{In-gel digestion and mass spectrometry analysis}

The in-gel digestion of proteins for mass spectrometric characterization was performed as published previously (47). After the tryptic peptide mixture was dissolved with $0.5 \%$ trifluoroacetic acid, peptide mass analysis was performed using an AB4800 MALDI-TOF/TOF mass spectrometer (Applied Biosystems). The mass spectra were externally calibrated with a peptide standard from Applied Biosystems. Based on the National Center for Biotechnology Information 
(NCBI) human databases, the mass spectra were analyzed with a $50 \mathrm{ppm}$ mass tolerance by GPS Explorer version 2.0.1 and Mascot version 1.9.

\section{Plasmid constructs and transfections}

The EA.hy926 or HBMEC endothelial cells were cultured in six-well plates in the growth medium and transfected with plasmid DNA encoding Prxl, siPrxl, siE6AP, pRK5-HAUbiquitin-K48R (17604; Addgene), or an empty plasmid control using Attractene (Qiagen). After transfection for 2 days, the cells were collected for related experiments. To express the active-site cysteine-to-alanine mutant of E6AP in endothelial cells, p3869HA-E6AP C833A cells (8649; Addgene) were used. The C-A mutation was introduced at the site of E6AP C833 $(22,27)$. The K48R mutant ubiquitin was obtained from Dr. Guanghui Wang (Soochow University) (27). All the constructs were confirmed by sequencing.

\section{Lentiviral vectors preparation for brain delivery}

To construct a lentiviral vector expressing Prx1, two complementary Prxl DNA oligonucleotides were synthesized and inserted into the EcoRI-BamHI site of transfer vector $p C D H$-CMV-MCS-EF1-CopGFP under the control of promoter $C M V$. The constructed vector was transformed into DH5a Escherichia coli and isolated with minipreps plasmid purification system (Promega). A large production of LVPrxl was prepared by transfection of human kidney 293T cells. In brief, 293T cells were cotransfected with a mixture containing packaging plasmid ( $\left.p C D / N L-B H^{*} D D D\right)$, envelope plasmid $(p L T R-G)$, and transfer vector and Trans-EZ. For high-titer virus stocks, the supernatant of cells was collected at $72 \mathrm{~h}$ after transfection, low-speed centrifuged, filtered, and ultracentrifuged. The titer of LV-Prxl stock was determined by transduction of HOS cells with serial dilutions of concentrated lentivirus and analyzing integrated viral DNA copies per cell by quantitative polymerase chain reaction. The lentiviral vectors coding for GFP without Prxl were prepared in a similar manner, as described above, and used as a control (LV-GFP). In addition, we used a lentivirusmediated RNA interference approach to achieve the inhibition of E6AP levels in the brain. The short hairpin RNA (shRNA)-mediated Ube3a knockdown vectors were constructed by subcloning the U6 promoter-sh-Ube $3 a$ cassette into the AgeI-EcoRI sites of the $p$ Lenti-CMV vector.

The lentiviral vector encoding mouse Prxl (LV-GFPPrxl), LV-GFP, or sh-E6AP was injected into the right lateral ventricle over a 10 -min duration using a Hamilton microsyringe with the coordinates of $0.5 \mathrm{~mm}$ caudal to the bregma, $1 \mathrm{~mm}$ lateral to the midline, and $3 \mathrm{~mm}$ depth from the skull surface under the guidance of a stereotaxic instrument. Two weeks after the introduction of the viral vectors, the MCAO mice model was prepared as previously reported (51). All lentivirus batches used for experiments had comparable titers ranging from $1 \times 10^{8}$ to $1 \times 10^{9}$ integration units $/ \mathrm{ml}$. Virus suspensions were stored at $-80^{\circ} \mathrm{C}$ until use and were briefly centrifuged and kept on ice immediately before injection.

\section{RNA interference}

Prxl siRNAs or E6AP siRNAs was introduced into EA.hy926 cells with the transfection medium according to the manufacturer's instructions. The control set of EA.hy926 cells was transfected with nontargeted siRNAs. The cells were collected for experiments $72 \mathrm{~h}$ after transfection. Knockdown was confirmed with Western blotting using whole cell lysates. siPrxl (sc-36177) and scramble negative control (sc-37007) were obtained from Santa Cruz Biotechnology: siE6AP (sense), 5'-GCCCAGACACAGAA AGGUUTT-3'; scramble negative control (siCont-1, sense), 5'-UUGCGGGUCUAAUCACCGATT-3'.

\section{Annexin V/PI flow cytometry analysis}

Flow cytometric assays to evaluate apoptosis by Annexin V/PI (BioVision) staining were performed essentially as previously described, following the manufacturer's instruction. Briefly, endothelial cells were transfected with Prxl siRNAs for $48 \mathrm{~h}$ before exposure to $6 \mathrm{~h}$ OGD. Annexin V-FITC and PI were added to the cell suspension and incubated at room temperature for $10 \mathrm{~min}$ in the dark. For each sample, at least $1 \times 10^{4}$ cells were analyzed using a FACSCalibur flow cytometer (BD Biosciences).

\section{TUNEL assay}

In situ DNA fragmentation was assessed using a TUNEL staining combined with 4',6-diamidino-2-phenylindole (DAPI) counterstain. Images were recorded after counterstaining with DAPI (nuclei marker), and endothelial cells were identified by phase image. Endothelial cells were imaged using $20 \times$ objectives. The apoptotic response was expressed as the percentage of TUNEL-positive endothelial cells/the total number of nuclei counted after DAPI staining. The results represented the average of a minimum of three experiments, and a minimum of 600 cells were counted per experiment.

\section{Cell fractionation, immunoprecipitation, and immunoblotting analysis}

Immunoblotting was carried out in endothelial cell lysates after determination of protein concentrations using the Bradford's solution. The cell lysates containing equivalent amounts of protein were applied to 10\%-13.5\% acrylamide denaturing gels (SDS-polyacrylamide gel electrophoresis [PAGE]) (15). Proteins were then transferred to an immobilon polyvinylidene difluoride membrane for $1 \mathrm{~h}$ at $50 \mathrm{~V}$. Membranes were blocked in $20 \mathrm{~m} M$ Tris- $\mathrm{HCl}$ (PH 7.4), $150 \mathrm{mM} \mathrm{NaCl}$, and $0.1 \%$ Tween 20 (TBS-T) containing 5\% fat-free milk powder for $1 \mathrm{~h}$ and immunodetected with antibodies to HSP27 monoclonal antibody (1:1000), Prx 1 polyclonal antibody (1:5000), (Abcam); HO-1 (1:1000), Phospho-AKT (1:1000), Phospho-ERK (1:3000), Phospho-JNK (1:1000), Phospho-P38 (1:1000), Phospho-FKHR (1:3000), and cleaved Caspase-3 (1:1000, polyclonal antibody; Cell Signaling Technology); procaspase-3 (1:2000), PARP-1 (1:2000), and ubiquitin (1:1000, polyclonal antibody; Santa Cruz Biotechnology); ZO-1 and Occludin (1:1000; Invitrogen); E6AP (1:3000) and $\beta$-actin (1:5000, monoclonal antibody; Sigma-Aldrich). After incubation for $12 \mathrm{~h}$, membranes were incubated with the appropriate horseradish peroxidase-conjugated secondary antibody. Immunoreactivity was visualized by enhanced chemiluminescence (Amersham Life Science). The Prx1 ubiquitylation assays were performed essentially as described previously (46). Briefly, cells were treated with $5 \mu M$ MG132 (Calbiochem) 
or with dimethyl sulfoxide (DMSO; control) for $30 \mathrm{~min}$ before OGD. Immunoprecipitates were analyzed by immunoblotting, using either anti-ubiquitin or anti-Prx1 antibody to detect ubiquitylated Prx1. In addition, E6AP immunoprecipitates from the lysates were probed with anti-nitrotyrosine antibody.

\section{Experimental animals}

Male C57 mice, weighing 20-23 g, were obtained from the Zhejiang Medical Animal Centre (Hangzhou, China). Mice were housed under climate-controlled conditions with a 12-h light/dark cycle and provided with standard food and water. Animals were acclimated to their environment for at least 1 week before initiating the experimental protocols. All experimental protocols and animal handling procedures were performed in accordance with the National Institutes of Health (NIH) guidelines for the care and use of laboratory animals and were approved by the Committee for Animal Experiments at the Zhejiang University in China.

\section{tMCAO model}

The transient/reperfusion MCAO model was used to resemble stroke in humans $(3,5)$, and the surgery was carried out as previously described (18). Animal procedures were approved by the Committee on Animal Experiments at the Zhejiang University. The rectal temperature was monitored throughout the surgery, and the body temperature was maintained at $37^{\circ} \mathrm{C} \pm 0.5^{\circ} \mathrm{C}$ with a heating pad. Neurological deficit tests were carried out at $24 \mathrm{~h}$ after tMCAO, including neurological scores and rotarod test. Neurological scores were determined $24 \mathrm{~h}$ after tMCAO using a previously described scoring system (45). Rotarod test, which started 3 days before the surgery to train five times every day, was performed to examine the motor coordination. The rotarod time (s) that mice persisted on the rotarod after ischemia was recorded; the data were expressed as the mean duration of five trials at $24 \mathrm{~h}$ after tMCAO. The brain infarct area of mice $24 \mathrm{~h}$ after ischemia was evaluated from scanned digital images of Nissl-stained brain sections using Image $\mathbf{J}$ software (NIH).

\section{Evaluation of $B B B$ damage}

The loss of BBB integrity was also verified by the leakage of Texas red-conjugated dextran from microvessels after intravenous injection. Texas red-dextran $(70 \mathrm{kDa})$ solution $(0.1 \%$ in phosphate-buffered saline [PBS], $5 \mathrm{ml} / \mathrm{kg})$ was intravenously administered via the tail vein at $22 \mathrm{~h}$ after the onset of MCAO. The mice were perfused transcardially with saline as above. After decapitation, brains were prepared according to the immunohistochemical methods, and Texas red-dextran leakage was determined by immunofluorescence staining (red fluorescence).

\section{Confocal immunofluorescence staining and analysis}

For immunofluorescence analysis in cultured endothelial cells, cells were fixed in $4 \%$ formaldehyde/PBS as previously reported (16). Cells were labeled with Prx1 (1:300, polyclonal antibody; Abcam), Nitrotyrosine (1:200, monoclonal antibody; Millipore), E6AP (1:300, polyclonal antibody; Invitrogen), and ubiquitin (1:200, monoclonal antibody; Cell Signaling Technology), followed by immunofluorescence using a standard protocol from PerkinElmer Life Sciences,
Inc. Nuclei were stained with DAPI dihydrochloride bisbenzimide $(5 \mu M)$. Immunolocalization and changes in Prx1, E6AP, and nitrotyrosine in cultured endothelial cells were visualized by confocal microscopy (Zeiss LSM 510).

For immunohistochemistry, mice were anesthetized at the time of sacrifice and transcardially perfused with $4 \%$ paraformaldehyde in PBS as previously described (16). The whole brains were immediately removed and post-fixed overnight at $4^{\circ} \mathrm{C}$. Then, brains were cut into $35-\mu \mathrm{m}$-thick serial sections using a vibratome. Sections were incubated at room temperature in PBS with $0.01 \%$ Triton-X100 for $30 \mathrm{~min}$ and for $1 \mathrm{~h}$ in $3 \%$ bovine serum albumin (BSA) in PBS. For immunolabeling, the brain slices were incubated with antibodies targeting Prx1 (1:300; Abcam), CD31 (1:200; Santa Cruz Biotechnology), Claudin5 (1:200; Invitrogen), E6AP (1:300; Sigma-Aldrich), NeuN (1:300), and Nitrotyrosine (1:200) (Millipore) overnight at $4^{\circ} \mathrm{C}$. After washing, the sections were incubated with Alexa fluor 488-conjugated anti-rabbit IgG (1:400) and Alexa fluor 594-conjugated antimouse IgG (1:400) (Invitrogen) in (Tris-NaCl-blocking) TNB buffer (1:400). In addition, the oxidative fluorescent indicator dihydroethidium was used to evaluate in situ $\mathrm{O}_{2}{ }^{\bullet-}$ generation as previously reported (45). Immunofluorescence was visualized by using a Zeiss LSM 510 confocal microscope.

\section{Statistical analysis}

The data were analyzed with $t$-tests when means between two groups were compared. For multigroup comparisons, statistical significance was determined using one-way ANOVA followed by a post hoc Tukey's test or Dunnett's comparison to control. All data are expressed as the mean \pm SEM. A value of $p<0.05$ was considered to be significant.

\section{Acknowledgments}

This work was supported in part by the National Natural Science Foundation of China (81120108023, 91232705, 81202533); the Zhejiang Provincial Qianjiang Talent Plan (2012R10036); the Zhejiang Provincial Natural Science Foundation of China (R2100281); NIH grants (NHLBI HL68686, NIDDK DK-49870, and DK-36079).

\section{Author Disclosure Statement}

No competing financial interests exist.

\section{References}

1. Aracena P, Tang W, Hamilton SL, and Hidalgo C. Effects of S-glutathionylation and S-nitrosylation on calmodulin binding to triads and FKBP12 binding to type 1 calcium release channels. Antioxid Redox Signal 7: 870-881, 2005.

2. Armulik A, Genové G, Mäe M, Nisancioglu MH, Wallgard E, Niaudet C, He L, Norlin J, Lindblom P, Strittmatter K, Johansson BR, and Betsholtz C. Pericytes regulate the blood-brain barrier. Nature 468: 557-561, 2010.

3. Braeuninger S and Kleinschnitz C. Rodent models of focal cerebral ischemia: procedural pitfalls and translational problems. Exp Transl Stroke Med 1: 8, 2009.

4. Brunet Simioni M, De Thonel A, Hammann A, Joly AL, Bossis G, Fourmaux E, Bouchot A, Landry J, Piechaczyk M, and Garrido C. Heat shock protein 27 is involved in SUMO-2/3 modification of heat shock factor 1 and thereby 
modulates the transcription factor activity. Oncogene 28: 3332-3344, 2009.

5. Carmichael ST. Rodent models of focal stroke: size, mechanism, and purpose. NeuroRx 2: 396-409, 2005.

6. Chae HZ, Kang SW, and Rhee SG. Isoforms of mammalian peroxiredoxin that reduce peroxides in presence of thioredoxin. Methods Enzymol 300: 219-226, 1999.

7. Chae HZ, Oubrahim H, Park JW, Rhee SG, and Chock PB. Protein glutathionylation in the regulation of peroxiredoxins: a family of thiol-specific peroxidases that function as antioxidants, molecular chaperones, and signal modulators. Antioxid Redox Signal 16: 506-523, 2012.

8. Coe H, Bedard K, Groenendyk J, Jung J, and Michalak M. Endoplasmic reticulum stress in the absence of calnexin. Cell Stress Chaperones 13: 497-507, 2008.

9. del Zoppo GJ. . The neurovascular unit, matrix proteases, and innate inflammation. Ann N Y Acad Sci 1207: 46-49, 2010.

10. Fisher AB. Peroxiredoxin 6: a bifunctional enzyme with glutathione peroxidase and phospholipase $\mathrm{A}_{2}$ activities. Antioxid Redox Signal 15: 831-844, 2011.

11. Gan Y, Ji X, Hu X, Luo Y, Zhang L, Li P, Liu X, Yan F, Vosler P, Gao Y, Stetler RA, and Chen J. Transgenic overexpression of peroxiredoxin-2 attenuates ischemic neuronal injury via suppression of a redox-sensitive prodeath signaling pathway. Antioxid Redox Signal 17: 719$732,2012$.

12. Geraerts M, Eggermont K, Hernandez-Acosta P, GarciaVerdugo JM, Baekelandt V, and Debyser Z. Lentiviral vectors mediate efficient and stable gene transfer in adult neural stem cells in vivo. Hum Gene Ther 17: 635-650, 2006.

13. Girouard H, Park L, Anrather J, Zhou P, and Iadecola C. Cerebrovascular nitrosative stress mediates neurovascular and endothelial dysfunction induced by angiotensin II. Arterioscler Thromb Vasc Biol 27: 303-309, 2007.

14. Guo X, Yamada S, Tanimoto A, Ding Y, Wang KY, Shimajiri S, Murata Y, Kimura S, Tasaki T, Nabeshima A, Watanabe T, Kohno K, and Sasaguri Y. Overexpression of peroxiredoxin 4 attenuates atherosclerosis in apolipoprotein E knockout mice. Antioxid Redox Signal 17: 1362-1375, 2012.

15. Han F, Ali Raie A, Shioda N, Qin ZH, and Fukunaga K. Accumulation of beta-amyloid in the brain microvessels accompanies increased hyperphosphorylated tau proteins following microsphere embolism in aged rats. $\mathrm{Neu}$ roscience 153: 414-427, 2008.

16. Han F, Chen YX, Lu YM, Huang JY, Zhang GS, Tao RR, Ji YL, Liao MH, Fukunaga K, and Qin ZH. Regulation of the ischemia-induced autophagy-lysosome processes by nitrosative stress in endothelial cells. J Pineal Res 51: 124135, 2011.

17. Han F, Shirasaki Y, and Fukunaga K. Microsphere embolisminduced endothelial nitric oxide synthase expression mediates disruption of the blood-brain barrier in rat brain. $J$ Neurochem 99: 97-106, 2006.

18. Han F, Tao RR, Zhang GS, Lu YM, Liu LL, Chen YX, Lou YJ, Fukunaga K, and Hong ZH. Melatonin ameliorates ischemic-like injury-evoked nitrosative stress: Involvement of HtrA2/PED pathways in endothelial cells. $J$ Pineal Res 50: 281-291, 2011.

19. Hu BR, Martone ME, Jones YZ, and Liu CL. Protein aggregation following transient cerebral ischemia. J Neurosci 20: 3191-3199, 2000.

20. Jakobsson $\mathbf{J}$ and Lundberg C. Lentiviral vectors for use in the central nervous system. Mol The 13: 484-493, 2006.
21. Kakihana T, Nagata K, and Sitia R. Peroxides and peroxidases in the endoplasmic reticulum: integrating redox homeostasis and oxidative folding. Antioxid Redox Signal 16: 763-771, 2012.

22. Kao WH, Beaudenon SL, Talis AL, Huibregtse JM, and Howley PM. Human papillomavirus type 16 E6 induces self-ubiquitination of the E6AP ubiquitin-protein ligase. J Virol 74: 6408-6417, 2000.

23. Kim SY, Kim TJ, and Lee KY. A novel function of peroxiredoxin 1 (Prx-1) in apoptosis signal-regulating kinase 1 (ASK1)-mediated signaling pathway. FEBS Lett 582: 1913-1918, 2008.

24. Kim YJ, Ahn JY, Liang P, Ip C, Zhang Y, and Park YM. Human prx1 gene is a target of Nrf2 and is upregulated by hypoxia/reoxygenation: implication to tumor biology. Cancer Res 67: 546-554, 2007.

25. Kisucka J, Chauhan AK, Patten IS, Yesilaltay A, Neumann C, Van Etten RA, Krieger M, and Wagner DD. Peroxiredoxin 1 prevents excessive endothelial activation and early atherosclerosis. Circ Res 103: 598-605, 2008.

26. Leblanc GG, Golanov E, Awad IA, and Young WL. Biology of Vascular Malformations of the Brain NINDS Workshop Collaborators. Biology of vascular malformations of the brain. Stroke 40: e694-e702, 2009.

27. Liu C, Fei E, Wang H, Tao R, Iwata A, Nukina N, Zhou J, and Wang G. Assembly of lysine 63-linked ubiquitin conjugates by phosphorylated-synuclein implies lewy body biogenesis. J Biol Chem 282: 14558-14566, 2007.

28. Liu G, Feinstein SI, Wang Y, Dodia C, Fisher D, Yu K, Ho $\mathrm{YS}$, and Fisher AB. Comparison of glutathione peroxidase 1 and peroxiredoxin 6 in protection against oxidative stress in the mouse lung. Free Radic Biol Med 49: 1172-1181, 2010.

29. Liu QB, Liu LL, Lu YM, Tao RR, Huang JY, Han F, and Lou YJ. The induction of reactive oxygen species and loss of mitochondrial Omi/HtrA2 is associated with S-nitrosoglutathione-induced apoptosis in human endothelial cells. Toxicol Appl Pharmacol 244: 374-384, 2010.

30. Manczak M, Mao P, Calkins MJ, Cornea A, Reddy AP, Murphy MP, Szeto HH, Park B, and Reddy PH. Mitochondria-targeted antioxidants protect against amyloidbeta toxicity in Alzheimer's disease neurons. J Alzheimers Dis 20: S609-S631, 2010.

31. Mowbray AL, Kang DH, Rhee SG, Kang SW, and Jo H. Laminar shear stress up-regulates peroxiredoxins (PRX) in endothelial cells: PRX 1 as a mechanosensitive antioxidant. J Biol Chem 283: 1622-1627, 2008.

32. Nakamura $\mathrm{T}$ and Lipton SA. S-nitrosylation of critical protein thiols mediates protein misfolding and mitochondrial dysfunction in neurodegenerative diseases. Antioxid Redox Signal 14: 1479-1492, 2011.

33. Nasu J, Murakami K, Miyagawa S, Yamashita R, Ichimura T, Wakita T, Hotta H, Miyamura T, Suzuki T, Satoh T, and Shoji I. E6AP ubiquitin ligase mediates ubiquitindependent degradation of peroxiredoxin 1. J Cell Biochem 111: 676-685, 2010.

34. Neumann CA, Krause DS, Carman CV, Das S, Dubey DP, Abraham JL, Bronson RT, Fujiwara Y, Orkin SH, and Van Etten RA. Essential role for the peroxiredoxin $\operatorname{Prdx} 1$ in erythrocyte antioxidant defence and tumour suppression. Nature 424: 561-565, 2003.

35. Pitts A, Dailey K, Newington JT, Chien A, Arseneault R, Cann T, Thompson LM, and Cumming RC. Dithiol based compounds maintain expression of antioxidant protein 
peroxiredoxin 1 that counteracts toxicity of mutant hungtington. J Biol Chem 287: 22717-22729, 2012.

36. Quaegebeur A, Segura I, and Carmeliet P. Pericytes: bloodbrain barrier safeguards against neurodegeneration? Neuron 68: 321-323, 2010.

37. Quaegebeur A, Lange C, and Carmeliet P. The neurovascular link in health and disease: molecular mechanisms and therapeutic implications. Neuron 71: 406-424, 2011.

38. Rabilloud T, Heller M, Gasnier F, Luche S, Rey C, Aebersold R, Benahmed $\mathrm{M}$, Louisot $\mathrm{P}$, and Lunardi J. Proteomics analysis of cellular response to oxidative stress. Evidence for in vivo overoxidation of peroxiredoxins at their active site. J Biol Chem 277: 1939619401, 2002.

39. Rani V, Neumann CA, Shao C, and Tischfield JA. Prdx1 deficiency in mice promotes tissue specific loss of heterozygosity mediated by deficiency in DNA repair and increased oxidative stress. Mutat Res 735: 39-45, 2012.

40. Riddell JR, Maier P, Sass SN, Moser MT, Foster BA, and Gollnick SO. Peroxiredoxin 1 stimulates endothelial cell expression of VEGF via TLR4 dependent activation of HIF-1 $\alpha$. PLoS One 7: e50394, 2012.

41. Rizzo MT and Leaver HA. Brain endothelial cell death: modes, signaling pathways, and relevance to neural development, homeostasis, and disease. Mol Neurobiol 42: 52-63, 2010.

42. Rott R, Szargel R, Haskin J, Bandopadhyay R, Lees AJ, Shani V, and Engelender S. $\alpha$-Synuclein fate is determined by USP9X-regulated monoubiquitination. Proc Natl Acad Sci U S A 108: 18666-186671, 2011.

43. Satoh M, Fujimoto S, Haruna Y, Arakawa S, Horike H, Komai N, Sasaki T, Tsujioka K, Makino H, and Kashihara N. NAD (P) h oxidase and uncoupled nitric oxide syntase are major sources of glomerular superoxide in rats with experimental diabetic nephropathy. Am J Physiol Renal Physiol 288: F1144-F1152, 2005.

44. Schreibelt G, van Horssen J, Haseloff RF, Reijerkerk A, van der Pol SM, Nieuwenhuizen O, Krause E, Blasig IE, Dijkstra CD, Ronken E, and de Vries HE. Protective effects of peroxiredoxin-1 at the injured blood-brain barrier. Free Radic Biol Med 45: 256-264, 2008.

45. Shioda N, Han F, Moriguchi S, and Fukunaga K. Constitutively active calcineurin mediates delayed neuronal death through Fas-ligand expression via activation of NFAT and FKHR transcriptional activities in mouse brain ischemia. J Neurochem 102: 1506-1517, 2007.

46. Shirakura M, Murakami K, Ichimura T, Suzuki R, Shimoji T, Fukuda K, Abe K, Sato S, Fukasawa M, Yamakawa Y, Nishijima M, Moriishi K, Matsuura Y, Wakita T, Suzuki T, Howley PM, Miyamura T, and Shoji I. E6AP ubiquitin ligase mediates ubiquitylation and degradation of hepatitis C virus core protein. J Virol 81: 1174-1185, 2007.

47. Sultana R, Perluigi M, Newman SF, Pierce WM, Cini C, Coccia R, and Butterfield DA. Redox proteomic analysis of carbonylated brain proteins in mild cognitive impairment and early Alzheimer's disease. Antioxid Redox Signal 12: 327-336, 2010.

48. Tan KH, Harrington S, Purcell WM, and Hurst RD. Peroxinitrite mediates nitric oxide-induced blood-brain barrier damage. Neurochem Res 29: 579-587, 2004.

49. Tao RR, Ji YL, Lu YM, Fukunaga K, and Han F. Targeting nitrosative stress for neurovascular protection: new implications in brain diseases. Curr Drug Targets 13: 272-284, 2012.
50. Wilcox CS and Pearlman A. Chemistry and antihypertensive effects of tempol and other nitroxides. Pharmacol Rev 60: 418-469, 2008.

51. Zhang GS, Tian Y, Huang JY, Tao RR, Liao MH, Lu YM, Ye WF, Wang R, Fukunaga K, Lou YJ, and Han F. The $\gamma$-Secretase blocker DAPT reduces the permeability of the blood-brain barrier by decreasing the ubiquitination and degradation of occludin during permanent brain ischemia. CNS Neurosci Ther 19: 53-60, 2012.

Address correspondence to: Dr. Feng Han Institute of Pharmacology, Toxicology and Biochemical Pharmaceutics Zhejiang University Hangzhou 310058 China

E-mail: changhuahan@zju.edu.cn

Date of first submission to ARS Central, April 18, 2013; date of final revised submission, November 12, 2013; date of acceptance, December 2, 2013.

\begin{tabular}{|c|}
\hline 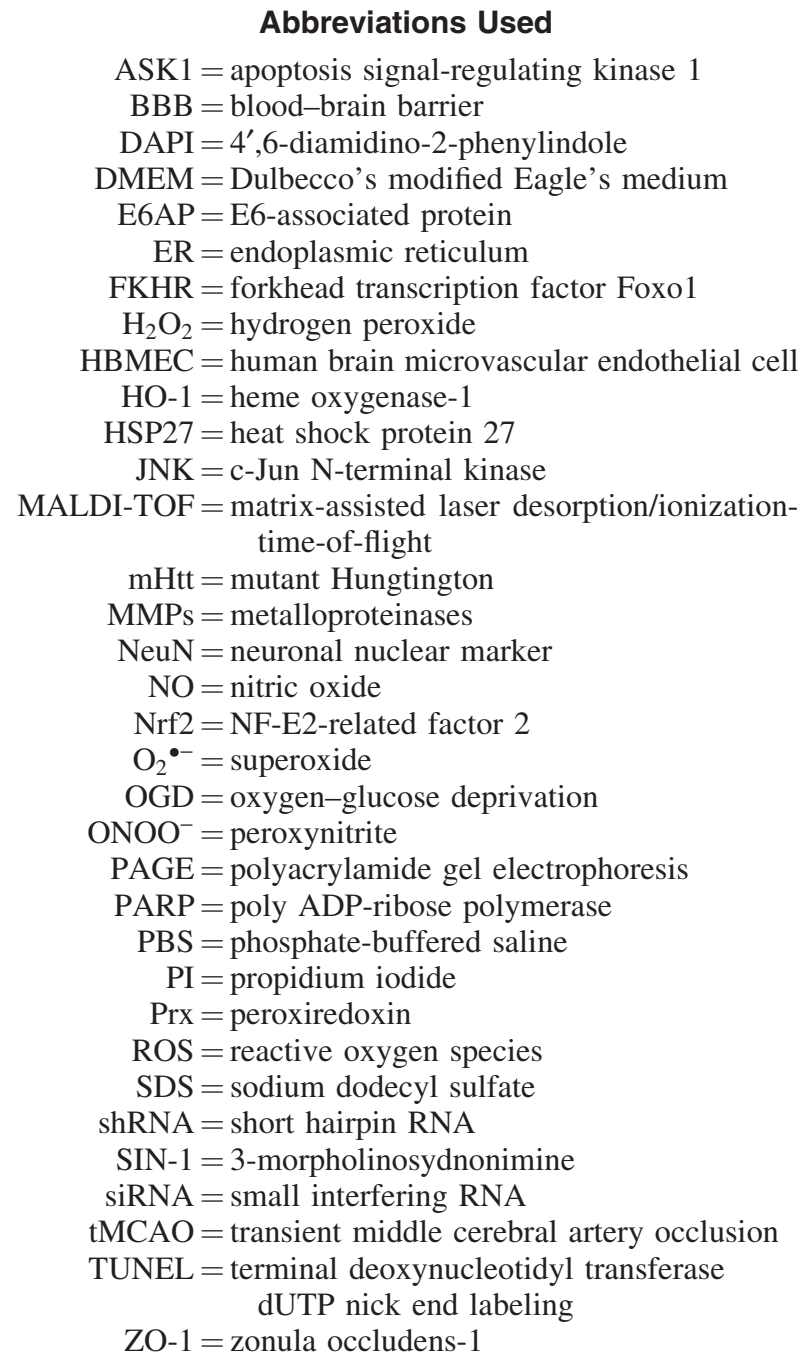 \\
\hline
\end{tabular}

